\title{
AVALIAÇÃO DAS PROPRIEDADES MECÂNICAS E DA RESISTÊNCIA À CORROSÃO ELETROQUÍMICA DO AÇO ASTM A572 E DE JUNTAS SOLDADAS
}

\author{
Fernando Vidal dos Santos ${ }^{1}$ \& José Rubens Gonçalves Carneiro ${ }^{2}$
}

\begin{abstract}
RESUMO
SANTOS, F.V.; CARNEIRO, J.R.G. Avaliação das Propriedades Mecânicas e da Resistência À Corrosão Eletroquímica do aço ASTM A572 e de Juntas Soldadas. Perspectivas Online: Exatas \& Engenharia, v. 09, n. 25, p. 20 - 48, 2019.

A demanda por materiais que combinassem alta resistência mecânica associada a melhor soldabilidade, tenacidade e resistência à corrosão atmosférica impulssionou a criação dos aços microligados. Este trabalho teve como objetivo avaliar a estrutura, as propriedades mecânicas e a resistência à corrosão eletroquímica numa solução de ácido sulfúrico do aço microligado ASTM A572 Grau 5- antes e após processos de soldagem GMAW - MAG e FCAW. A fim de analisar a macroestrutura e a microestrutura foram utilizadas as técnicas de estereomicroscopia e microscopia ótica, respectivamente. A avaliação das propriedades mecânicas se deu através de ensaios de microdureza e de tração. Utilizando a modelagem tridimensional computacional com $\mathrm{O}$ software Abaqus, foi possível realizar simulações por meio da técnica de elementos finitos, que reproduz o ensaio

graficamente a partir da curva tensão versus deformação verdadeira proveniente do ensaio mecânico de tração. Não foram observadas descontinuidades nas juntas soldadas e valores de microdureza e das propriedades mecânicas de tração não indicaram fragilização do material. Verificou-se que a simulação numérica é eficiente e confiável quando comparados com os ensaios mecânicos de tração. As curvas seguiram de forma paralela no regime elástico, tendo valores um pouco menores. Os resultados do ensaio de corrosão eletroquímica mostraram que a soldagem GMAW - MAG resultou num metal de solda com resistência à corrosão maior que do metal base, mostrando que a escolha do processo de soldagem e do metal de adição é importante não só para estabelecer propriedades mecânicas apropriadas, mas também resistência à corrosão eletroquímica.
\end{abstract}

Palavras-chave: ASTM A572, Juntas Soldadas, Ensaio de Tração, Elementos finitos, Resistência à corrosão. 


\begin{abstract}
Demand for materials that combined high mechanical strength associated with improved weldability, toughness and atmospheric corrosion resistance drove the development of microalloyed steels. The objective of this work was to evaluate the structure, mechanical properties and resistance to electrochemical corrosion in sulfuric acid solution of an ASTM A572 Grade 5 microalloyed steel before and after GMAW - MAG and FCAW welding processes. In order to analyze the macrostructure and microstructure the techniques of stereomicroscopy and optical microscopy were used, respectively. The mechanical properties were evaluated by microhardness and tensile tests. Using computational three-dimensional modeling with Abaqus software, it was possible to perform
\end{abstract}

ABSTRACT

simulations using the finite element technique, which reproduces the test graphically from the stress versus true strain curve from the mechanical tensile test. No discontinuities were observed in welded joints and microhardness values and tensile mechanical properties did not indicate material brittleness. Numerical simulation was found to be efficient and reliable when compared to mechanical tensile tests. The curves followed parallel in the elastic regime, having slightly smaller values. The results of the electrochemical corrosion test showed that GMAW - MAG welding resulted in a weld metal with higher corrosion resistance than the base metal, showing that the choice of welding process and filler metal is important not only to establish mechanical properties appropriate, but also electrochemical corrosion resistance.

Keywords: ASTM A572, Welded Joints, Tensile Test, Finite Elements, Corrosion Resistance.

\footnotetext{
${ }^{1,2}$ Pontifícia Universidade Católica de Minas Gerais, R. Dom José Gaspar, CEP: 30.535-901- Coração Eucarístico, Belo Horizonte - MG, Brasil;

(1) e-mail: fv.vidal@hotmail.com

(2) e-mail: joserub@pucminas.br

Data de recebimento: 10/09/19. Aceito para publicação: 11/09/19.
} 


\section{INTRODUÇÃO}

O aço ASTM A572 Grau 50 é produzido em forma de chapas e perfis laminados a quente com uma resistência à corrosão atmosférica superior a dos aços carbono. Ele atende aos requisitos fundamentais dos aços microligados estruturais tais como: melhorar a resistência à corrosão atmosférica e maior resistência mecânica em relação aos aços carbono. Este é um fator importante a considerar, porque a utilização de seções mais finas pode significar vida mais curta da estrutura, a não ser que a redução da seção seja acompanhada por um aumento correspondente da resistência à corrosão do material (FERRER, 2013).

Atualmente, o uso de ferramentas de simulação numérica tem se ampliado na indústria em geral, com o objetivo de otimizar o projeto do produto ainda na fase inicial e de reduzir o tempo de introdução do produto no mercado, diminuição de custos e a verificação de aplicação de novos materiais. Para melhorar o desempenho e a durabilidade de uma peça ou produto é vital ter um bom projeto, deve-se estudar a geometria e as propriedades do material desse objeto, pois as falhas nas peças está diretamente relacionada com a intensidade de tensão crítica do material. No meio acadêmico, além do suporte à tecnologia da indústria, as ferramentas de simulação podem atuar como fortes aliados no entendimento de conceitos. Nesse sentido, o Método dos Elementos Finitos (FEM) é uma poderosa ferramenta de trabalho para o engenheiro (RIVA, 2017).

O ensaio de tração é um dos testes mecânicos mais comuns. É utilizado na seleção de materiais e na determinação de propriedades mecânicas importantes para aplicações de engenharia. Frequentemente as propriedades de tração são utilizadas também na previsão do comportamento de materiais solicitados de maneira não uniaxial (DAVIS, 2019).

A soldagem realizada pelos processos MAG e MIG têm sido alvo de estudos para o aço ASTM A572 com o objetivo de avaliar o desempenho da junta soldada (GORNI, 2008). Com a finalidade de reduzir o nível de descontinuidade da junta soldada, as instruções de processo estabelecem passes de raiz, de enchimento e acabamento em estruturas. Para equipamentos sujeitos a vibrações costuma-se utilizar o processo FCAW - MIG com arame 81 T1-A1 ( consumível B - MS "B" ) e para demais equipamentos GMAW - MAG arame ER 70S-6 ( consumível A - MS “A” ) (PADILHA \& AMBRÓSIO, 1985).

Dentro deste contexto, neste trabalho foram implementados modelos de simulação do ensaio de tração utilizando o FEM, com os corpos de prova do aço ASTM A572 em chapas metal base e junta soldada. Sendo assim um dos objetivos deste trabalho é avaliar a simulação do ensaio de tração destrutivo em comparação com a modelagem tridimensional do software Abaqus de corpos de provas do aço ASTM A572 metal base e junta soldada, no regime elástico. Através da comparação dos resultados de simulação foi possível avaliar a validade destes modelos. São modelos simples, e foram analisados aspectos que servem de base para outros trabalhos na área de simulação.

Poucos estudos foram realizados na avaliação da resistência à corrosão do metal base (MB) em comparação com os metais de solda (MSA \& MSB) em ambiente de $\mathrm{H}_{2} \mathrm{SO}_{4}(0,5 \mathrm{M})$ o que pode proporcionar perda de espessura por corrosão localizada tanto em juntas soldadas como no metal de base de equipamentos, tais como tubulação ou vaso de pressão (COLPAERT, 1994). O presente trabalho também teve por objetivo avaliar a resistência à corrosão do metal base e das juntas de aço ASTM A572 executadas com espessura de 6,3 mm, chanfro tipo "V",

Persp. Online: exatas \& eng., Campos dos Goytacazes, 25 (09) 20 - 48 - 2019

seer.perspectivasonline.com.br 
ângulo $60^{\circ}$, de acordo com AWS D1.1 de 2002 pelos processos GMAW - MAG com arame ER 70S-6 ( consumível A ) \& FCAW - MIG com arame 81 T1-A1 ( consumível B ).

\section{METODOLOGIA}

O trabalho foi desenvolvido em uma sequência operacional conforme as etapas:

Etapa I - Materiais, Preparação dos corpos de prova e Soldagem

Etapa II - Preparação Metalográfica

Etapa III - Ensaio de Microdureza Vickers

Etapa IV - Ensaio de Corrosão Eletroquímico

Etapa V - Ensaio de tração

Etapa IV - Simulações no software Abaqus do ensaio de tração

\subsection{Etapa I - Preparação dos Corpos de Prova e Soldagem}

As propriedades mecânicas do material deste trabalho (certificado do material) referenciado pelo seu fabricante do aço ASTM A572 (USIMINAS) são mostradas na Tabela 1.

Tabela 1: Propriedades mecânicas do aço ASTM A572 (Usiminas).

\begin{tabular}{c|c|c|c|c}
\hline Designação & $\sigma_{Y}(\mathbf{M P a})$ & $\sigma_{\mathrm{RT}}(\mathbf{M P a})$ & $\boldsymbol{\varepsilon}(\boldsymbol{\%})$ & $\left(\frac{\sigma_{Y}}{\sigma_{\mathrm{RT}}} \times 100\right)(\boldsymbol{\%})$ \\
\hline $\begin{array}{c}\text { ASTM A572-15-50-1 } \\
\text { USI-CIVI-350 }\end{array}$ & 453 & 609 & 21 & 74 \\
\hline
\end{tabular}

Os cortes dos corpos de prova para o metal base e soldagem foram realizados em máquina CNC de Oxicorte segundo a direção perpendicular à laminação e, em seguida, os corpos de prova para soldagem foram chanfrados em uma fresadora. Foi realizado os processos de soldagem MAG - GMAW \& MIG - FCAW semiautomáticos, que seguem os procedimentos e especificações de soldagem. 
Foram soldados 2 corpos-de-prova, com dimensões \#6,3 x 200 x $300 \mathrm{~mm}$, sendo uma 01 peça com o arame "A", e outra peça com o arame "B". As juntas qualificadas do aço ASTM A572 possuem espessura de $6,3 \mathrm{~mm}$, com tipo de chanfro "V", ângulo $60^{\circ}$, abertura de solda 3 $\mathrm{mm}$, de acordo com AWS D1.1 de 2002. Após soldagem, os corpos de prova foram usinados com dimensão final de \#5,0 x 20 x 180 mm conforme mostrado na Figura 1.

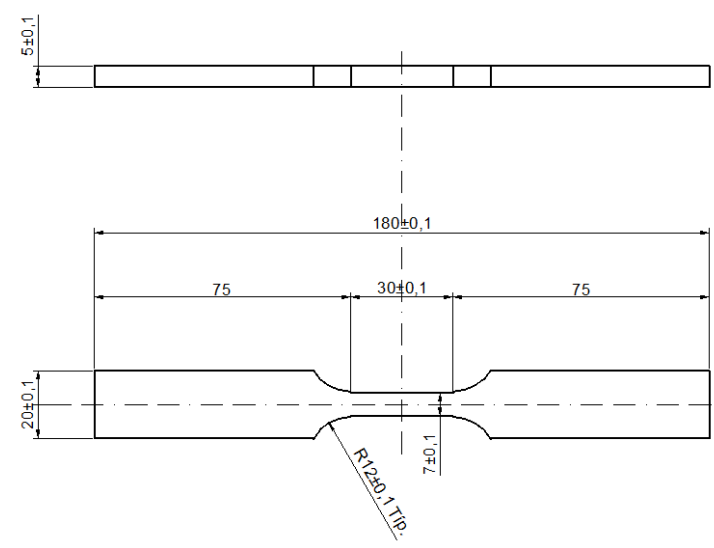

(a)

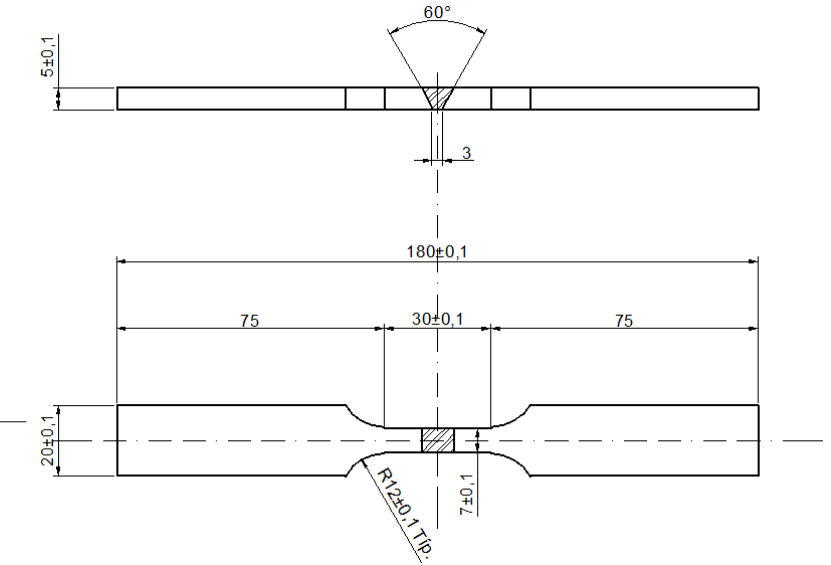

(b)

Figura 1: a) Desenho Final do Corpo de prova do metal base do Aço ASTM A572

(b) Desenho Final do Corpo de prova das juntas soldadas "A" e "B" do Aço ASTM A572

Utilizou-se os arames identificados como "A" para o arame ER 70S-6 com o processo de soldagem GMAW e "B" para o arame 81 T1-A1 com o processo de soldagem FCAW, diâmetros de 1,2 mm. A posição de soldagem foi plano-horizontal. A formulação do gás de proteção para o processo GMAW ocorreu com a seguinte proporção (75\% de $\operatorname{Ar} \& 25 \%$ de $\mathrm{CO}_{2}$ ) e para o processo de soldagem FCAW foi realizada com $\left(99,99 \%\right.$ de $\left.\mathrm{CO}_{2}\right)$. Para estes tipos de solda, verificaram-se a necessidade de utilização de babadores no início e no fim da solda, para evitar aumento do tamanho da ZTA nestas regiões. Após o posicionamento do corpo-de-prova no dispositivo, os parâmetros da máquina de solda foram regulados conforme procedimentos de soldagem, e executou-se as soldas dos corpo-de-prova, retirando as impurezas do cordão com uma escova de aço Figura 2.

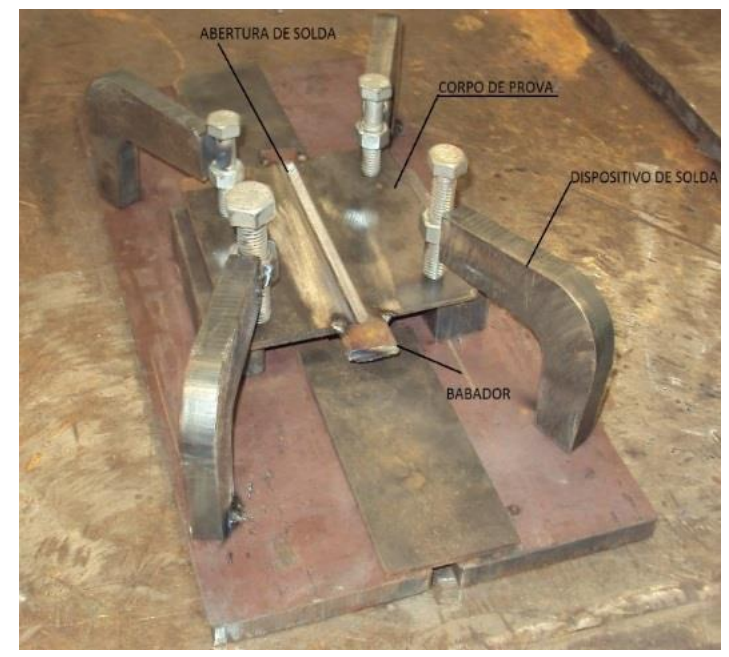

(a)

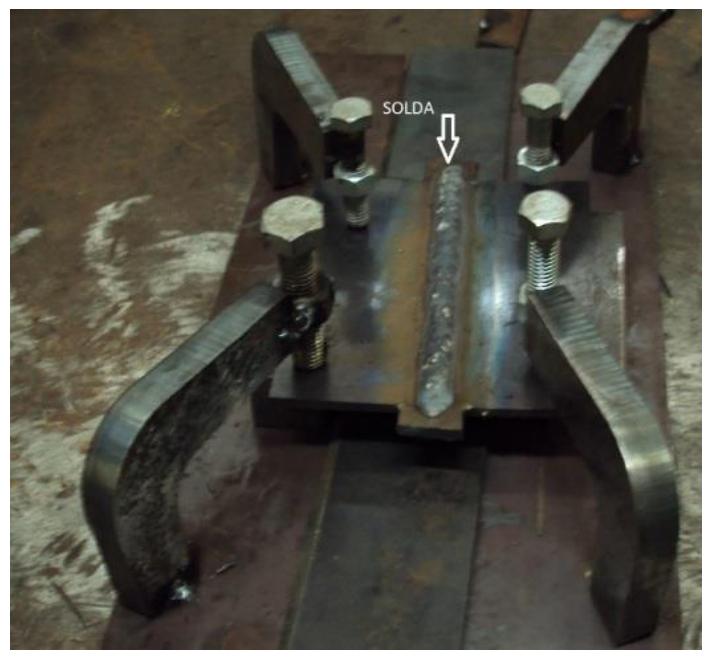

(b)

Figura 2: a) Posicionamento para solda do corpo-de-prova do aço ASTM A572

(b) Junta soldada do aço ASTM A572.

Persp. Online: exatas \& eng., Campos dos Goytacazes, 25 (09) 20 - 48 - 2019 seer.perspectivasonline.com.br 
Após o processo de soldagem em um dos lados, foi retirado o corpo-de-prova e feita a extração de raiz com uma lixadeira rotativa Figura 3. Após resfriamento por 30 minutos, realizou-se o ensaio de líquido penetrante, e, após 10 minutos, aplicou-se o revelador, conforme a Figura 4, seguido do processo de soldagem do lado da extração de raiz.

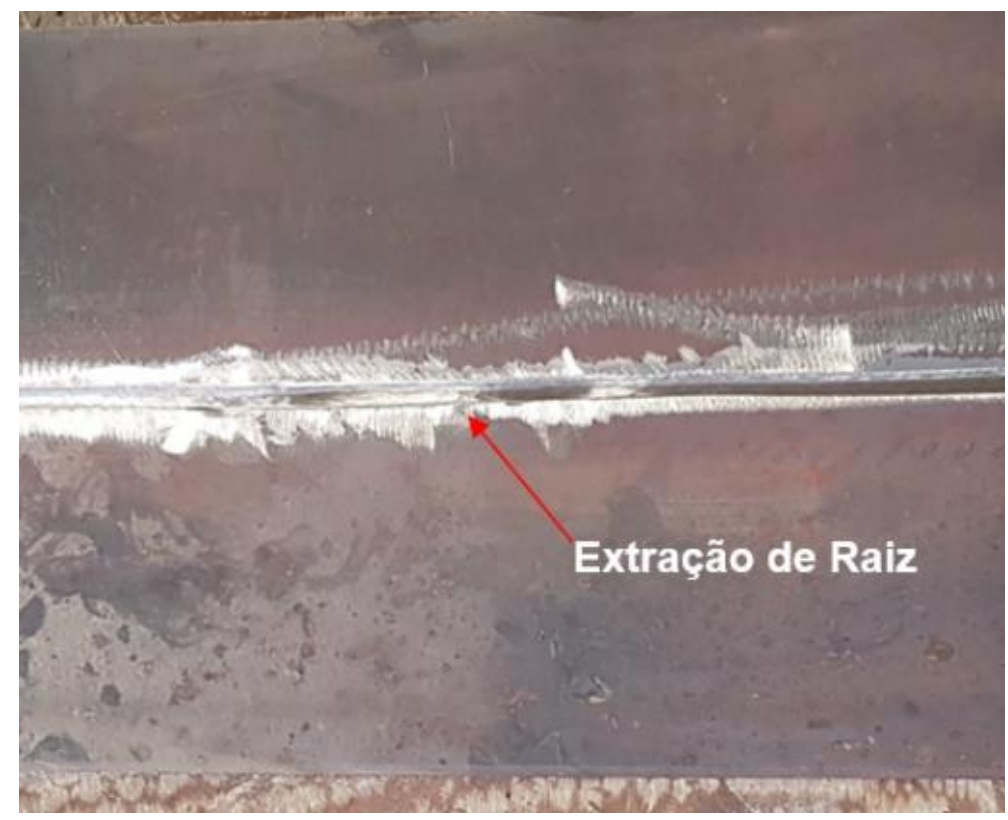

Figura 3: Extração da raiz de solda com lixadeira rotativa

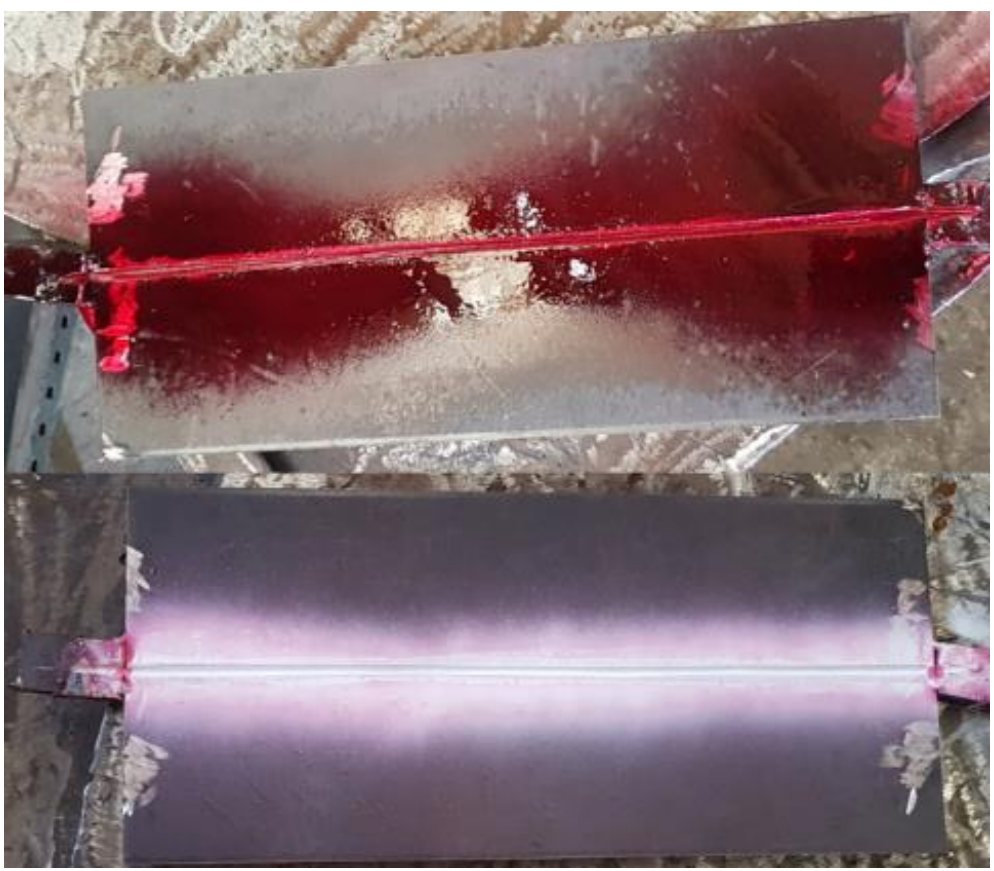

Figura 4: Ensaio de líquido penetrante

Para os corpos de com os arames do tipo "A" e do tipo "B", após a soldagem completa dos três passes (raiz, preenchimento e extração da raiz) foi realizado além dos ensaios de líquido penetrante o ensaio de ultrassom. O Quadro 1 apresenta os principais dados do ensaio de ultrassom utilizados para inspeção dos corpos de prova tipo "1" e "2". Não foram encontradas

Persp. Online: exatas \& eng., Campos dos Goytacazes, 25 (09) 20 - 48 - 2019 seer.perspectivasonline.com.br 
descontinuidades nas peças soldadas. Caso houvesse alguma descontinuidade, através deste ensaio a mesma seria detectada pela divergência que é o fenômeno que pode ser observado ao detectar um defeito pequeno com o feixe ultrassônico central do transdutor; que nesta condição, a amplitude do eco na tela do aparelho seria máxima.

Quadro 1: Principais dados do ensaio de ultrassom realizado nas juntas soldadas

\begin{tabular}{|l|l|l|l|}
\hline $\begin{array}{l}\text { Condições } \\
\text { superficiais }\end{array}$ & Escovado de & $\begin{array}{l}\text { Apêndice 12 - } \\
\text { Item 14.1 }\end{array}$ \\
\hline Aceitaçários \\
\hline $\begin{array}{l}\text { Calibração de } \\
\text { sensibilidade }\end{array}$ & Melcelulose & Normas aplicáveis & ASME VIII Div. 1 \\
\hline Tipo de ondas & Logitudinais/Transversais & $\begin{array}{l}\text { Método } \\
\text { ensaio }\end{array}$ & $\begin{array}{l}\text { Contato pulso eco } \\
03\end{array}$ \\
\hline Aparelho & Krakramer USM 35X5 & $\begin{array}{l}\text { Sensibilidade do } \\
\text { ensaio }\end{array}$ & Furo Ø 2,4 mm \\
\hline $\begin{array}{l}\text { Blocos } \\
\text { calibração }\end{array}$ & ASME 20 & Eco refletor & $\begin{array}{l}80 \% \text { da altura da } \\
\text { tela }\end{array}$ \\
\hline
\end{tabular}

\subsection{Etapa II - Preparação Metalografica}

As amostras para metalografia foram cortadas em serra de fita, e retirados os corpos de prova para os ensaios metalográficos e mecânicos. As amostras do metal base (MB), metal de solda do tipo "A" (MSA) e do tipo "B" (MSB) foram fresadas e, posteriormente, preparadas em lixas com granulometrias de 180, 220, 320, 400, 500, 600 e 1000 mesh. Em seguida, foi realizado polimento de acabamento em feltro impregnado com pasta de diamante de dimensão de 9,3 e $1 \mu \mathrm{m}$.

Posteriormente para a análise metalográfica do corpo de prova foi executado o embutimento a quente das amostras em baquelite. A análise metalográfica avaliou as microestruturas do metal base (MB), metal de solda do tipo "A" e metal de solda do tipo "B".

O reativo químico utilizado para revelar a macro e microestrutura foi Nital 2\%. Essas amostras foram observadas em lupa Discovery e em microscópio ótico, marca Zeiss, dotado de microcâmera e software Axion-Vision de quantificação.

\subsection{Etapa III - Ensaio de Microdureza Vickers}

Perfis de microdureza Vickers foram levantados nas amostras embutidas, do metal base (MB), metal de solda do tipo "A" (MSA) e metal de solda do tipo "B" (MSB). O ensaio foi realizado em microdurômetro Vickers carga de 0,2 kgf em uma amostra embutida de $10 \mathrm{~mm} x$ $10 \mathrm{~mm}$ e atacada com Nital $2 \%$.

A amostra com metal de base foi medida realizando 10 impressões aleatórias em ponto diversos e aleatórios numa amostra de $10 \mathrm{~mm}$ x $10 \mathrm{~mm}$ embutida e atacada quimicamente. As

Persp. Online: exatas \& eng., Campos dos Goytacazes, 25 (09) 20 - 48 - 2019 seer.perspectivasonline.com.br 
amostras soldadas com MSA e MSB foram medidas conforme Figura 5. Foram realizadas 3 medidas em cada uma das posições analisadas no cordão e com as distâncias indicadas na Figura 5 de $0,5 \mathrm{~mm}$ entre a mesma linha e $0,3 \mathrm{~mm}$ entre as linhas.

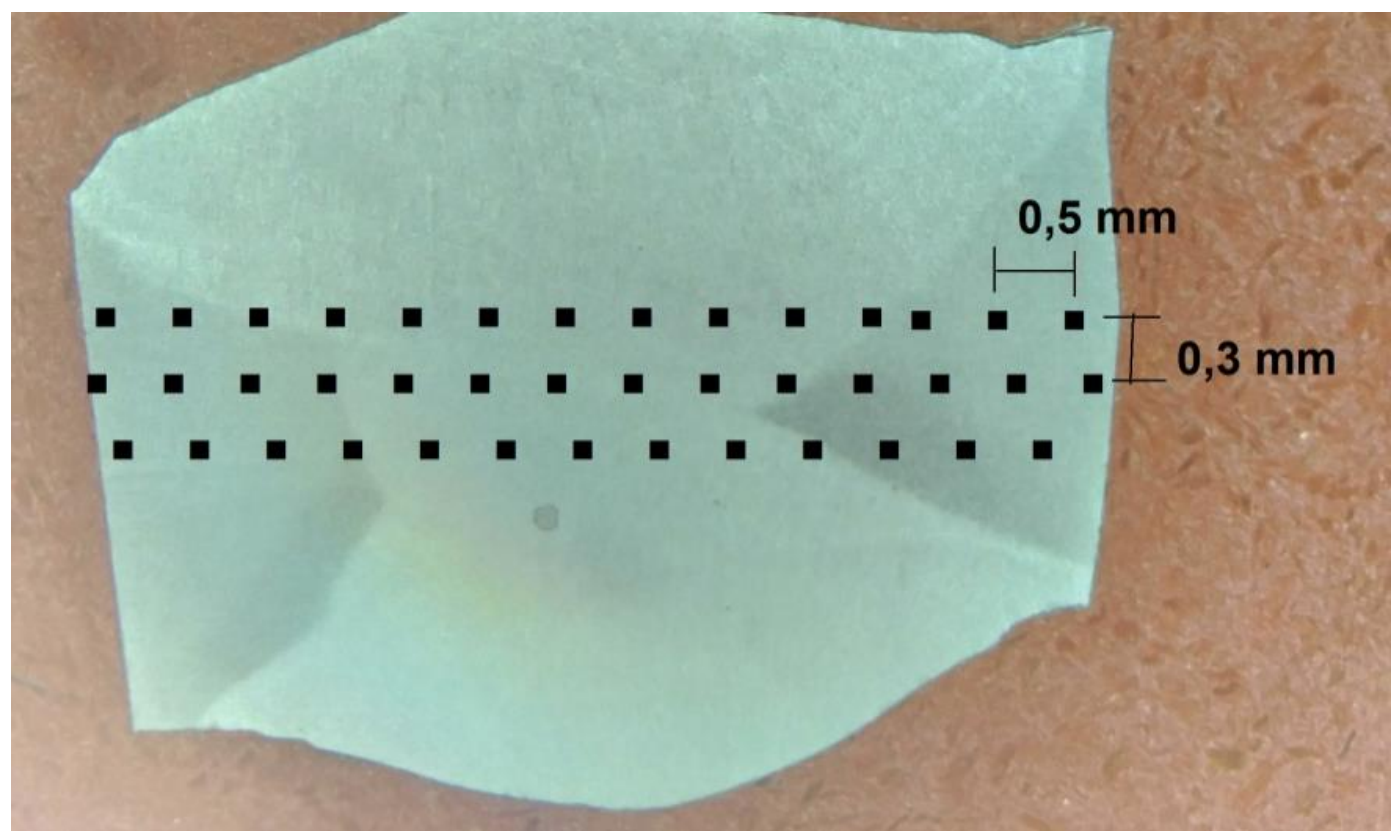

Figura 5: Esquema das medidas realizadas nas amostras soldadas com MSA e MSB do Aço ASTM A572

\subsection{Etapa IV - Ensaio de Corrosão Eletroquímico}

Durante a realização dos ensaios eletroquímicos utilizou-se a célula de corrosão eletroquímica tipo Flat Cell, cujo projeto e fabricação foi feito no departamento de engenharia mecânica da PUC mostrado na Figura 6.

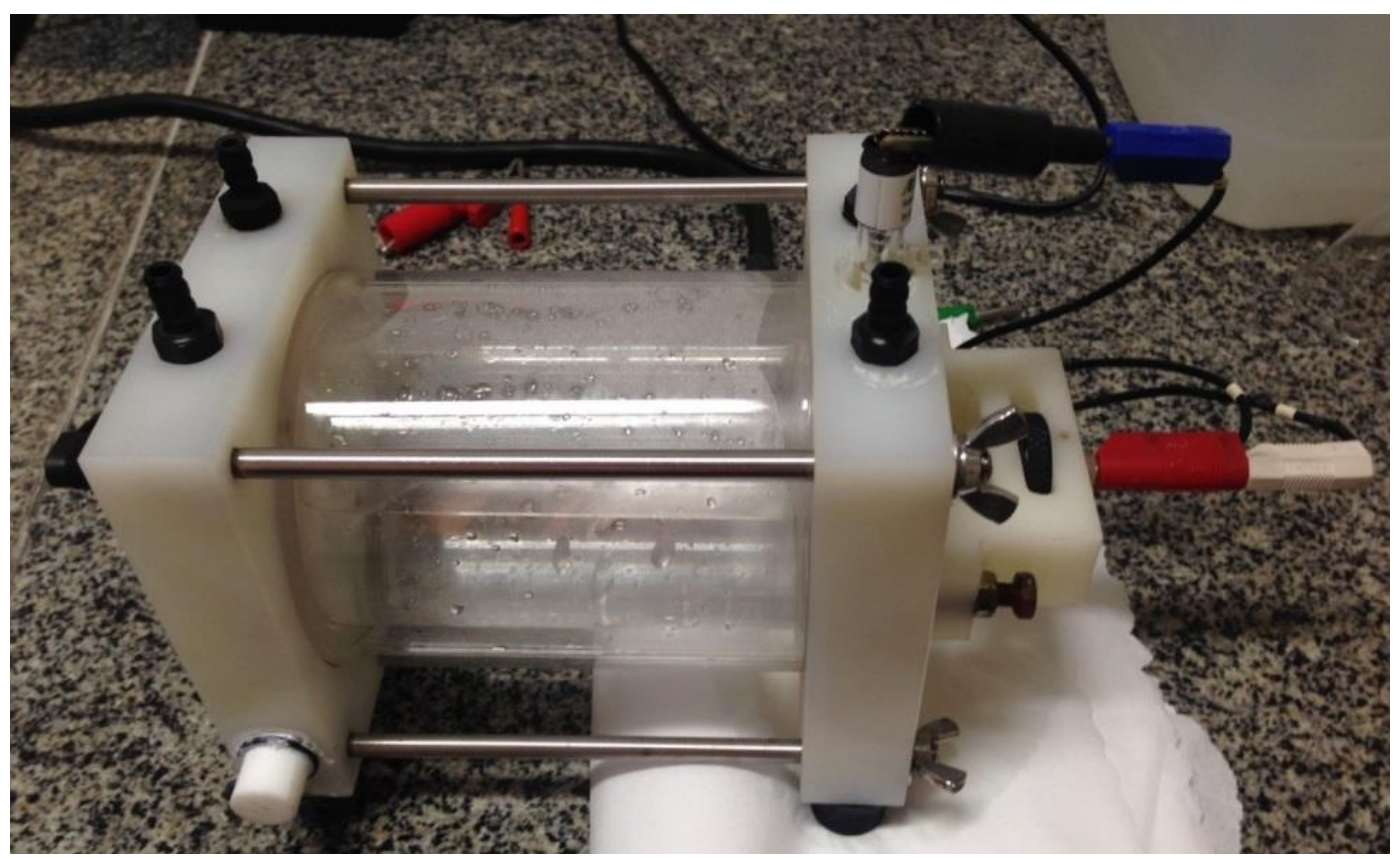

Figura 6: Célula de corrosão eletroquímica fabricada na PUC.

Persp. Online: exatas \& eng., Campos dos Goytacazes, 25 (09) 20 - 48 - 2019 seer.perspectivasonline.com.br 
Foi utilizada uma solução de ácido sulfúrico $0,5 \mathrm{moL} / \mathrm{L}\left(\mathrm{H}_{2} \mathrm{SO}_{4} 0,5 \mathrm{M}\right)$. O preparo desta solução consiste em diluir $27,7 \mathrm{~mL}$ de $\mathrm{H}_{2} \mathrm{SO}_{4}$, grau PA, em água destilada para $1000 \mathrm{~mL}$. $\mathrm{O}$ equipamento usado na realização dos ensaios de corrosão eletroquímica foi o potenciostato, modelo IviumStat, da Ivium Technologies B. V., acoplado "on-line" a um microcomputador e a célula eletroquímica com eletrodo de platina (auxiliar e medidor de corrente elétrica), eletrodo de calomelano saturado $\left(\mathrm{Hg}_{2} \mathrm{C}_{2}\right.$ sat., referência e aplicação de potencial) e eletrodo de trabalho (amostra a ser analisada).

Todos os ensaios foram conduzidos à temperatura ambiente e umidade relativa do ar de $40 \%$. Durante um período de 1 hora (3600 segundos) foram feitos levantamentos de curvas de estabilização de potencial de circuito aberto (OCP - Open Circuit Potential), comumente chamado de potencial de corrosão $\left(\mathrm{E}_{\text {corr }}\right)$ registrando-se a variação de $\mathrm{E}_{\text {corr }}$ vs. Tempo. Em seguida, a amostra foi submetida aos ensaios de levantamento dos diagramas de espectroscopia de impedância eletroquímica e das curvas de polarização potenciodinâmicas. As condições usadas na obtenção das curvas de polarização potenciodinâmicas tiveram como base procedimento da norma ASTM G5 (2013) estão listadas na Tabela 2. Os parâmetros físicoquímicos para os materiais metálicos são dados na Tabela 3.

Tabela 2: Condições usadas na obtenção da curva de polarização potenciodinâmica

\begin{tabular}{l|c}
\hline \multicolumn{1}{c|}{ CONDIÇÕES USADAS } & VALOR \\
\hline Potencial inicial de varredura & $-600 \mathrm{mV}(-0,6 \mathrm{~V})$ abaixo do potencial de circuito aberto \\
\hline Potencial final de varredura anódica & $2000 \mathrm{mV}(2,0 \mathrm{~V})$ \\
\hline Velocidade de varredura & $0,2 \mathrm{mV} / \mathrm{s}-0,002 \mathrm{~V} / \mathrm{s}$ \\
\hline
\end{tabular}

Tabela 3: Parâmetros físico-químicos utilizados

\begin{tabular}{l|c}
\multicolumn{1}{c|}{ PARÂMETROS } & MB, MSA e MSB \\
\hline Eq. wt. $(\mathrm{g})$ & 27,79 \\
\hline Densidade, $\rho\left(\mathrm{g} / \mathrm{cm}^{3}\right)$ & 7,82 \\
\hline
\end{tabular}

A obtenção dos parâmetros eletroquímicos correspondentes às curvas de polarização potenciodinâmicas e curvas de Tafel foi feita através do software IviumSoft, que gerencia também o levantamento das curvas de estabilização de potencial com tempo e dos diagramas de impedância eletroquímica. As condições usadas na obtenção dos diagramas de espectroscopia de impedância eletroquímica são listadas na Tabela 4. 
Tabela 4: Condições usadas na obtenção do diagrama de espectroscopia de impedância eletroquímica

\begin{tabular}{l|c}
\hline \multicolumn{1}{c|}{ CONDIÇÕES USADAS } & VALOR \\
\hline Faixa de frequência & $15 \mathrm{mHz}-10 \mathrm{kHz}$ \\
\hline Amplitude de voltagem (rms) & $5 \mathrm{mV} \mathrm{rms}$ \\
\hline Freqüência de leitura & 5 pontos/década \\
\hline
\end{tabular}

A interpretação dos resultados e análise dos diagramas de espectroscopia de impedância eletroquímica seguiram os procedimentos recomendados pela literatura específica (ASTM G 106, 2010; MATTOS, 1987; ORAZEM e TRIBOLLET, 2008; WOLYNEC, 2003).

\subsection{Etapa V - Ensaio de Tração}

O ensaio de tração foi realizado em uma máquina universal de ensaios. A configuração do ensaio foi feita pelo software Kratos, gerando um script de ensaio com registro de carga dinâmico e velocidade de ensaio de $150 \mathrm{kgf} / \mathrm{s}$. Foram realizados um ensaio para o corpo de prova do metal base (MB), um ensaio para o metal de solda do tipo "A" (MSA) e um ensaio para o metal de solda do tipo "B" (MSB) do aço ASTM A572 em chapas. Os ensaios de tração realizaram uma curva para cada tipo de corpo de prova. Após o ensaio os dados foram tratados no Excel, fazendo a transformação das curvas de engenharia para as curvas verdadeiras, obtendo os Limites de Resistência, Limites de Escoamento, Alongamentos e os parâmetros K (Coeficiente de Resistência) e n (Coeficiente de Encruamento) para cada tipo de corpo de prova (CALLISTER, 2002).

\subsection{Etapa VI - Simulações no software Abaqus do ensaio de tração}

A modelagem e simulação computacional no Abaqus do ensaio de tração dos corpos de prova do metal base (MB), metal de solda do tipo "A" (MSA) e metal de solda do tipo "B" (MSB) seguiram o fluxograma, mostrado na Figura 7.

Para esta modelagem foi utilizada a versão do Abaqus/CAE 2019. O programa é dividido em módulos, a modelagem e configuração seguem os passos a seguir:

No primeiro passo "a) Modulo Part" ocorreu a criação do arquivo.cae no Abaqus/CAE pelo caminho: File > New Model > Database e importação do arquivo criado no SOLIDWORKS do modelo 3D do corpo de prova com extensão IGS pelo caminho: File > Import > Sketch. Os desenhos dos corpos de prova como mostrado na Figura 1.a e 1.b foram realizados por meio do software SOLIDWORKS e posteriormente exportados para o software Abaqus conforme mostrado na Figura 8. 


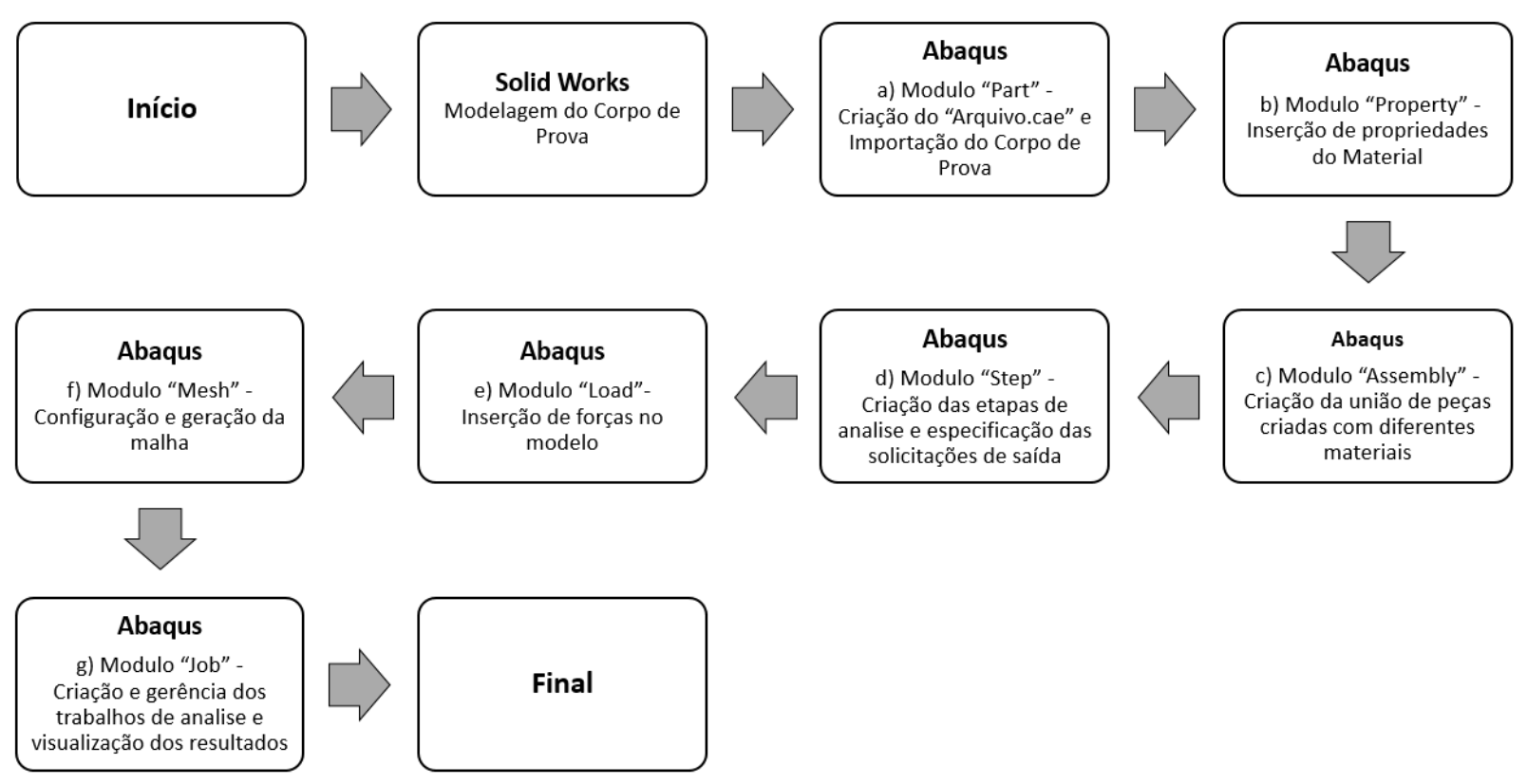

Figura 7: Fluxograma da modelagem e simulação computacional no Abaqus do ensaio de tração dos corpos de prova do metal base (MB), metal de solda do tipo "A" (MSA) e metal de solda do tipo "B" (MSB).

No segundo passo “b) Modulo Property” ocorreu a inserção das propriedades dos materiais. Neste passo foi definido quais são as características dos materiais das peças a serem analisadas. Foi adicionado pelo ícone > Section Manager os materiais nas peças, com as seguintes características:

Os materiais dos corpos de prova, conforme já descrito, é o ASTM A572, suas propriedades foram inseridas através de: $>$ "Elastic" Módulo de Elasticidade $=210000 \mathrm{GPa}$ e Coeficiente de Poisson $=0.3$. $>$ "Plastic" as Tabelas 5, 6 e 7 mostram os valores usados no programa Abaqus para a caracterização da plasticidade dos materiais. Os dados da região plástica do ensaio mecânico foram utilizados como base de dados para as simulações pelo método de elementos finitos. O material foi considerado homogêneo e sólido.

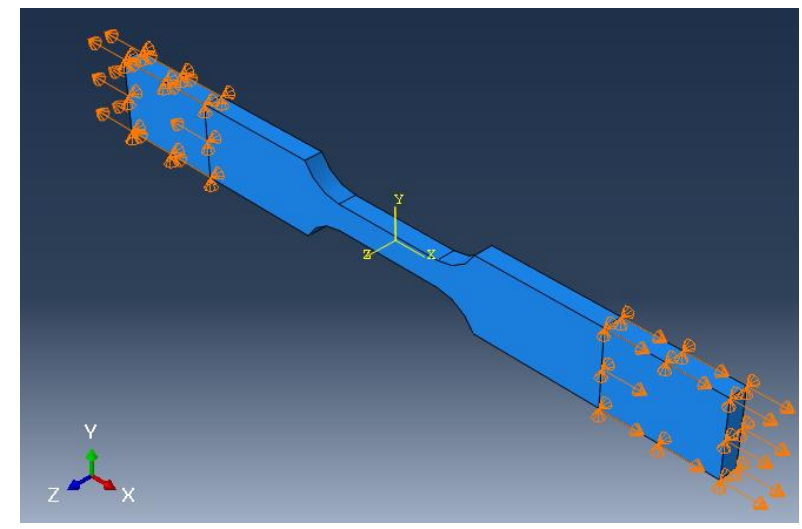

(a)

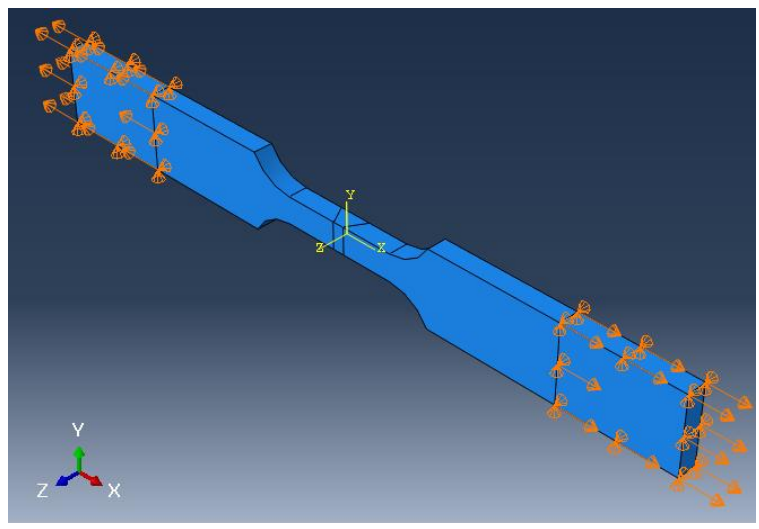

(b)

Figura 8: (a) Desenho do Corpo de prova do metal base no software Abaqus (b) Desenho do Corpo de prova das juntas soldadas "A" e "B"no software Abaqus 
A deformação plástica apresentada nas Tabelas 5, 6 e 7 foram calculadas segundo orientação do Abaqus, de acordo com a equação (1).

$$
\varepsilon_{\mathrm{pl}}=\varepsilon_{\mathrm{t}}-\varepsilon_{\mathrm{el}}=\varepsilon_{\mathrm{t}}-(\sigma / \mathrm{E})
$$

Onde, $\varepsilon_{\mathrm{pl}}$ é a deformação plástica verdadeira, $\varepsilon_{\mathrm{t}}$ é a deformação total verdadeira, $\varepsilon_{\mathrm{el}}$ é a deformação elástica verdadeira e $\sigma$ a tensão verdadeira correspondente.

Tabelas 5: Valores usados no programa Abaqus para a caracterização do material do Corpo de prova do metal base

\begin{tabular}{c|c}
\hline $\begin{array}{c}\text { Tensão Verdadeira } \\
(\mathbf{M P a})\end{array}$ & Deformação Verdadeira \\
\hline 419,00000 & 0,00000 \\
\hline 430,52631 & 0,06214 \\
\hline 450,64661 & 0,06820 \\
\hline 470,10526 & 0,07481 \\
\hline 490,64661 & 0,08266 \\
\hline 520,60150 & 0,09702 \\
\hline 549,02255 & 0,11720 \\
\hline 570,22556 & 0,14319 \\
\hline 580,96240 & 0,18462 \\
\hline 581,17293 & 0,18857 \\
\hline
\end{tabular}


Tabelas 6: Valores usados no programa Abaqus para a caracterização do material do Corpo de prova da juntas soldadas "A"

\begin{tabular}{c|c}
\hline $\begin{array}{c}\text { Tensão Verdadeira } \\
(\mathbf{M P a})\end{array}$ & Deformação Verdadeira \\
\hline 519,00000 & 0,00000 \\
\hline 549,97114 & 0,11073 \\
\hline 570,74437 & 0,12571 \\
\hline 580,61165 & 0,13539 \\
\hline 590,45008 & 0,14974 \\
\hline 591,92152 & 0,15281 \\
\hline 593,39296 & 0,15587 \\
\hline 595,90305 & 0,16500 \\
\hline 597,80727 & 0,18003 \\
\hline 598,00923 & 0,18104 \\
\hline
\end{tabular}

Tabelas 7: Valores usados no programa Abaqus para a caracterização do material do Corpo de prova da juntas soldadas " $\mathrm{B}$ "

\begin{tabular}{c|c}
\hline $\begin{array}{c}\text { Tensão Verdadeira } \\
(\mathbf{M P a})\end{array}$ & Deformação Verdadeira \\
\hline 432,80454 & 0,00000 \\
\hline 442,83148 & 0,05681 \\
\hline 476,11493 & 006521 \\
\hline 501,58635 & 0,07287 \\
\hline 510,26638 & 0,07582 \\
\hline 540,94582 & 0,08806 \\
\hline 565,99820 & 0,10203 \\
\hline 591,43968 & 0,12635 \\
\hline 600,14965 & 0,14344 \\
\hline 602,96318 & 0,16285 \\
\hline
\end{tabular}

Conforme o manual do Abaqus, é necessário também a configuração para os materiais referente à > "Ductile Damage" que deve ser especificada em $>$ Displacement at Failure = 0.02. Também foi configurado neste passo as seções dos materiais pelo caminho: > Create Section e > Assign Section. 
No terceiro passo “c) Modulo Assembly” ocorreu a inserção das propriedades das seções dos materiais às geometrias das seções selecionadas pelo ícone > Create instance. Para o corpo de prova da junta soldada "A" e "B do Aço ASTM A572 foram criadas duas seções, sendo que a primeira (1) seção possui as propriedades do metal base conforme Tabela 5 e a segunda (2) seção possui as propriedades das juntas soldadas "A" e "B conforme Tabela 6 e 7, cuja configuração é mostrada na Figura 9. Para o corpo de prova do metal base foi criada apenas uma seção com respectivas propriedades de acordo com a Tabela 5.

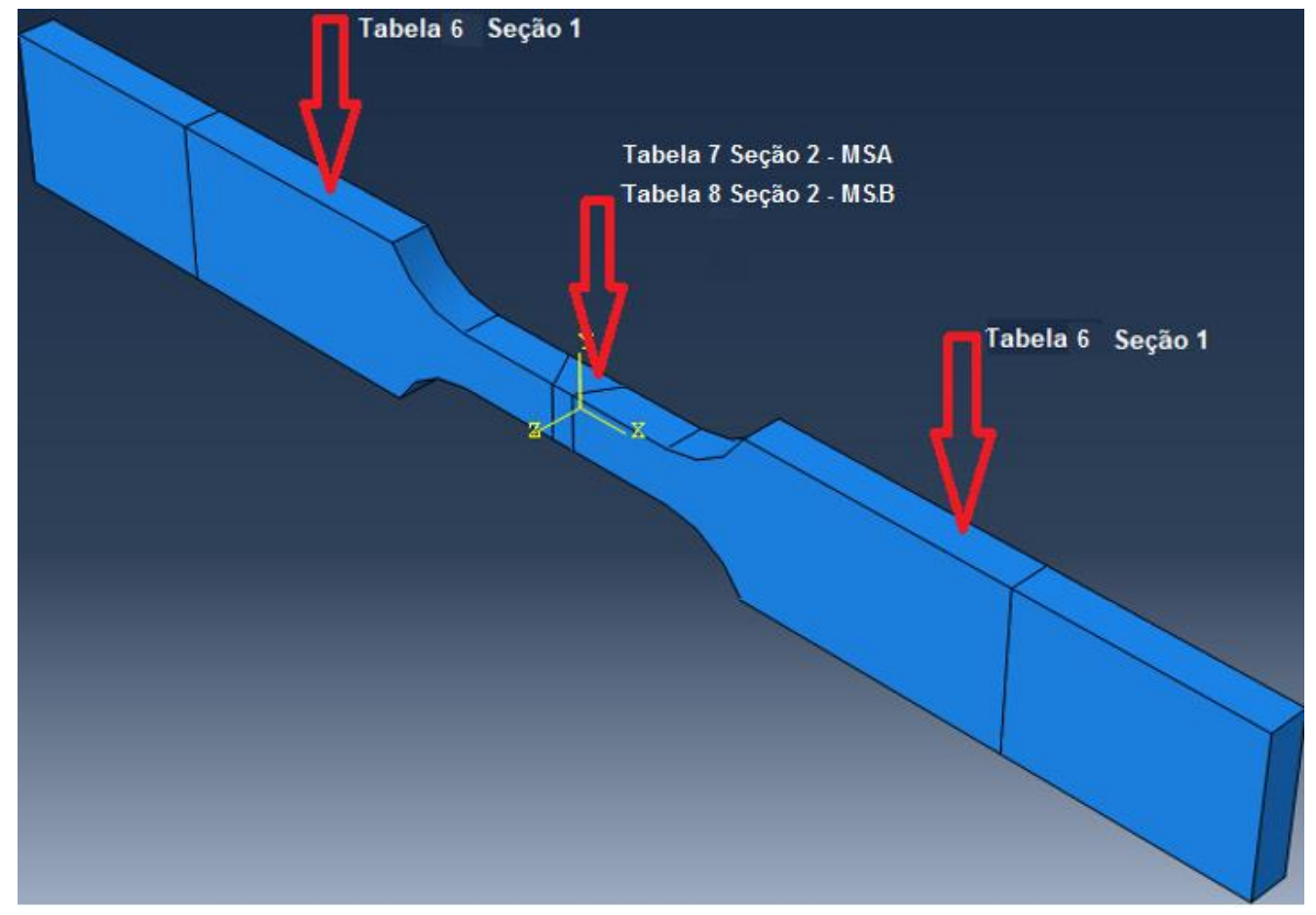

Figura 9: Desenho dos Corpos de prova mostrando as seções sendo que a primeira (1) seção possui as propriedades do metal base conforme tabela 6 e a segunda (2) seção possui as propriedades da junta soldada conforme tabela 7 e 8 para as juntas soldadas " $\mathrm{A}$ " e " $\mathrm{B}$

No quarto passo “d) Modulo Step” ocorreu a criação das etapas de análise e especificações das solicitações de saída e controles de análise. Conforme o manual do Abaqus, deve-se criar um Step Static Geral através do ícone > Create Step, e configurar os passos de análise, como: tipo; incremento inicial, mínimo e máximo. As configurações adotadas foram: Basic: Automatic stabilization > Specify dissipated energy fraction; Incrementation: Maximum number of incrementes:10000; Incremente size: initial: 0:02; minimum: 1e-009; Maximum: 1. Também foi configurada a saída das análises através do ícone > Field output, com os seguintes itens marcados: Stresses, Strain, Displacement/Velocity/Acceleration, Forces/Reactions, Contact, Volume/Thickness/Coordinates e State/Field/User/Time.

No quinto passo "e) Modulo Load” foi inserido os carregamentos nos modelos. Devese configurar através do ícone > Create Boundary Condition, e configurar os passos do carregamento. Para as simulações dos corpos de prova em chapa do aço ASTM A572 se aplicou um deslocamento $10 \mathrm{~mm}$ para se ter certeza do rompimento do material durante o processo, sendo tracionado por meio da aplicação do deslocamento desejado nas extremidades do corpo de prova virtual conforme mostrado nas Figuras 9, situação considerada quase estática devido à baixa velocidade de deslocamento.

Persp. Online: exatas \& eng., Campos dos Goytacazes, 25 (09) 20 - 48 - 2019 seer.perspectivasonline.com.br 
No sexto passo "f) Modulo Mesh" foram inseridas as malhas nos modelos. Deve-se configurar através do ícone > Seed edges > Seed Part > Assign Mesh Control > Mesh Part. Foi configurado o tamanho de $3 \mathrm{~mm}$ no $>$ Approximate global size: 3, para todos os corpos de prova. O Abaqus gera a malha automaticamente pelo ícone > Mesh Part.

No sétimo passo " $g$ ) Modulo Job" foi executada a simulação que cria e gerencia os trabalhos de análise e visualiza os resultados da análise através do ícone > Job Manager.

\section{RESULTADOS E DISCUSSÃO}

A Tabela 8 mostra as propriedades mecânicas dos resultados dos ensaios de tração do aço ASTM A572, sendo: Limite de Escoamento $\left(\sigma_{\mathrm{Y}}\right)$, Limite de Resistência verdadeira $\left(\sigma_{\mathrm{RT}}\right)$ e Alongamento $(\varepsilon)$ para os corpos de prova do metal base e juntas soldadas "A" e "B.

Tabela 8: Propriedades mecânicas dos resultados dos ensaios de tração do metal base e juntas soldadas "A" e "B.

\begin{tabular}{c|c|c|c|c}
\hline Material & $\sigma_{\mathrm{Y}}(\mathbf{M P a})$ & $\sigma_{\mathrm{RT}}(\mathbf{M P a})$ & $\varepsilon(\boldsymbol{\%})$ & $\left(\frac{\sigma_{\mathrm{Y}}}{\sigma_{\mathrm{RT}}} \times 100\right)(\boldsymbol{\%})$ \\
\hline Metal Base & 420 & 581 & 32 & 72 \\
\hline Solda A & 420 & 598 & 30 & 70 \\
\hline Solda B & 433 & 602 & 37 & 72 \\
\hline
\end{tabular}

A Tabela 9 mostra os resultados da composição química realizadas no espectrômetro ótico de emissão para o material ASTM A572 e para o metal de adição da junta soldada do material do Corpo de prova das juntas soldadas "A" e "B".

Tabelas 9: Composição química dos materiais utilizados (\% em peso)

\begin{tabular}{|c|c|c|c|c|c|c|c|c|c|c|c|c|c|c|c|c|}
\hline \multirow{2}{*}{ Material } & \multicolumn{16}{|c|}{ Elemento químico $\left(\times 10^{-3}\right)$} \\
\hline & $\mathrm{C}$ & $\mathrm{Si}$ & $\mathrm{Mn}$ & $\mathrm{P}$ & $\mathrm{S}$ & $\mathrm{Al}$ & $\mathrm{Cu}$ & $\mathrm{Nb}$ & V & $\mathrm{Ti}$ & $\mathrm{Cr}$ & $\mathrm{Ni}$ & Mo & $\mathrm{Ni}$ & $\mathrm{Pb}$ & $\mathrm{C}_{\mathrm{eq}}$ \\
\hline MB & 180 & 350 & 1510 & 16 & 8 & 22 & 10 & 14 & 2 & 14 & 20 & 10 & - & 5,7 & 1 & 430 \\
\hline Solda A & 3,0 & 881 & 1448 & 21,9 & 12 & 2,2 & 21,6 & - & 2,7 & - & 29,5 & 10,7 & 2,6 & - & - & - \\
\hline Solda B & 3,7 & 340 & 850 & 21 & 16 & - & - & - & - & - & - & 200 & 510 & - & - & - \\
\hline
\end{tabular}

$\mathrm{C}_{\mathrm{eq}}$ representa a composição química do carbono equivalente. Em soldagem, o carbono equivalente $\left(\% \mathrm{C}_{\mathrm{eq}}\right)$ é uma medida da temperabilidade do aço, e informa, também, a necessidade de pré e pós aquecimento após soldagem. Foi utilizada nesse trabalho a Equação 2, proposta pela AWS (American Welding Society). 


$$
\% \mathrm{C}_{\text {eq }}=\% \mathrm{C}+\left(\frac{\% \mathrm{Mn}+\% \mathrm{Si}}{6}\right)+\left(\frac{\% \mathrm{Cr}+\% \mathrm{Mo}+\% \mathrm{~V}}{5}\right)+\left(\frac{\% \mathrm{Cu}+\% \mathrm{Ni}}{15}\right)
$$

As adições de carbono e de outros elementos de liga, tais como $\mathrm{Mn}, \mathrm{Cr}, \mathrm{Si}, \mathrm{V}, \mathrm{Cu}$ e $\mathrm{Ni}$, tendem a aumentar a dureza, aumentar a temperabilidade e diminuir a soldabilidade. A AWS afirma que, para um carbono equivalente acima de $0,40 \%$ há um potencial de formação de trincas na zona termicamente afetada (ZTA) em soldas e cortes a chama. No entanto, normas de engenharia estrutural raramente usam o \% $\mathrm{C}_{\text {eq }}$, mas limitam o percentual máximo de certos elementos de liga.

\subsection{Macrografia das Juntas Soldadas}

As Figuras 10 e 11 apresentam a macrografia da seção transversal das juntas analisadas onde se evidencia os passes realizados e onde, também, é possível visualizar a extensão da ZTA cujo valor máximo não excede, de forma aproximada, os $0,5 \mathrm{~mm}$.

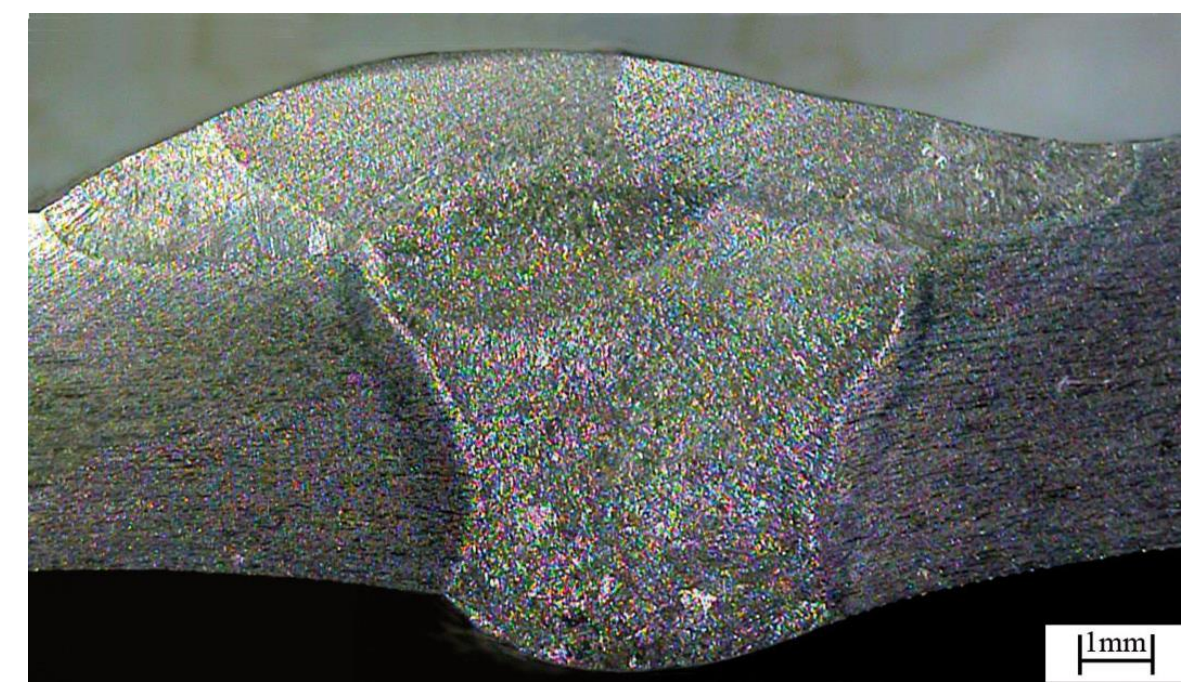

Figura 10: Macrografia da junta soldada para os corpos de prova do tipo "A". Ataque químico com Nital $2 \%$.

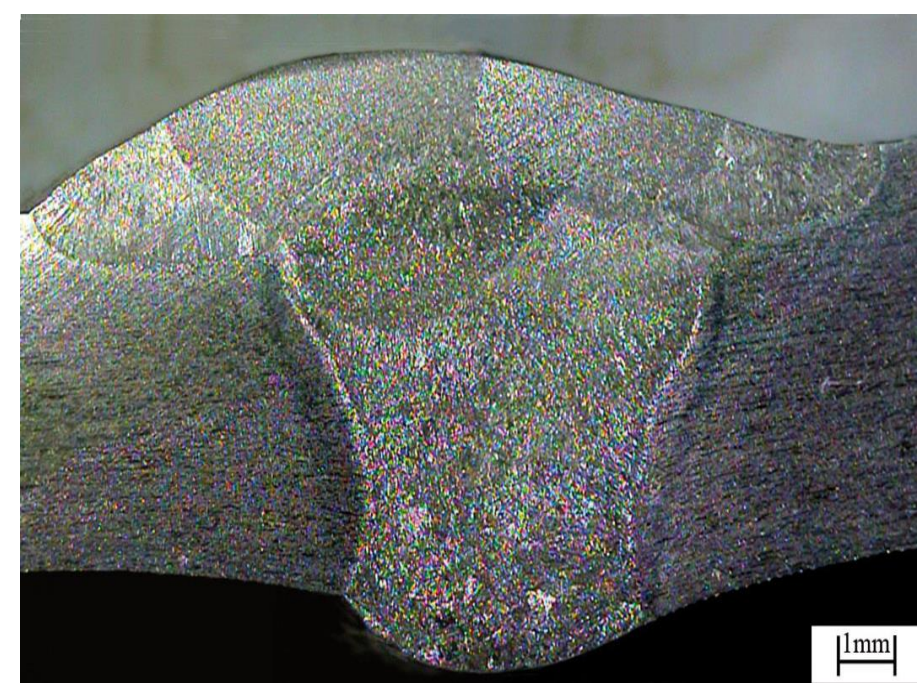

Figura 11: Macrografia da junta soldada para os corpos de prova do tipo "B". Ataque químico com Nital $2 \%$.

Persp. Online: exatas \& eng., Campos dos Goytacazes, 25 (09) 20 - 48 - 2019 seer.perspectivasonline.com.br 


\subsection{Micrografia das Juntas Soldadas}

As Figuras 12, 13, 14 apresentam as microestruturas características do metal base, zona fundida e zona termicamente afetada. A microestrutura do MB é constituída de bandas de ferrita poligonal e perlita. Na ZF pode-se observar a formação de grãos maiores em algumas regiões e outras contendo ferrita acicular. Ao comparar a ZTA do Tipo "A" com Tipo "B" observou-se que em ambos parte do bandeamento permaneceu.

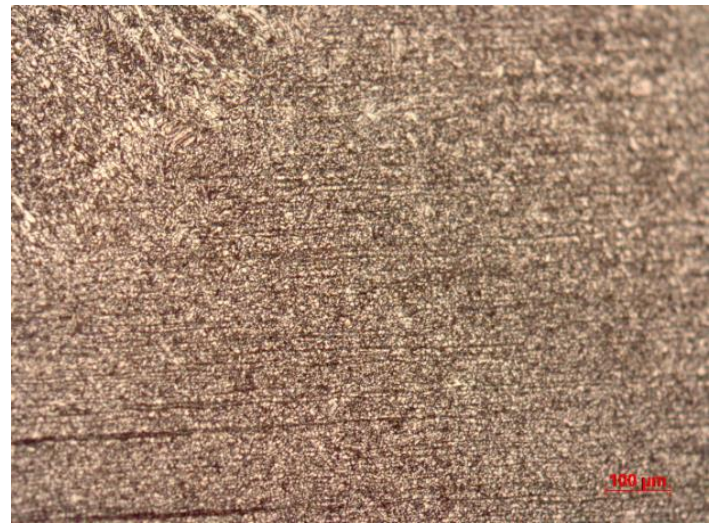

(a)

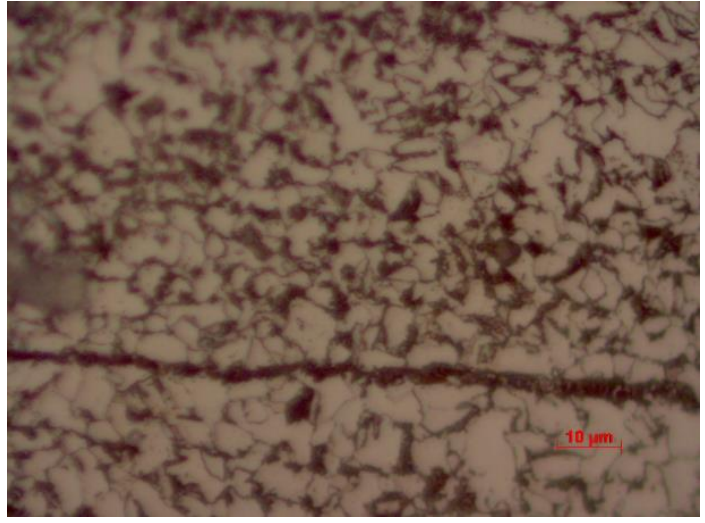

(b)

Figura 12: Microestrutura da junta soldada do metal base (MB) submetida ao processo de solda com metal (a) Tipo A e (b) Tipo B

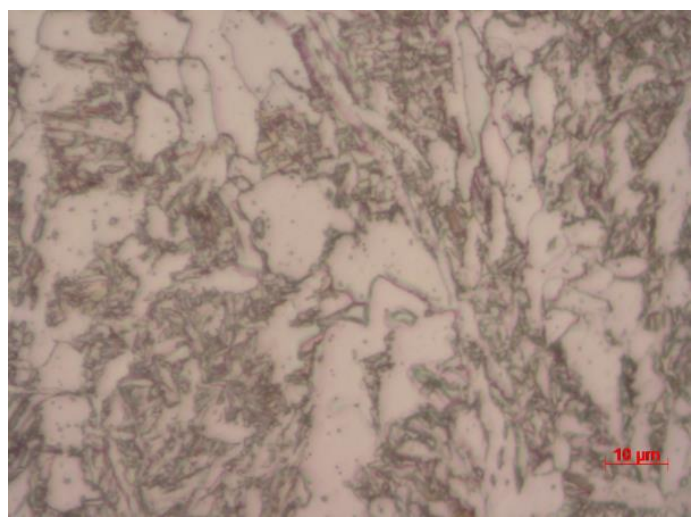

(a)

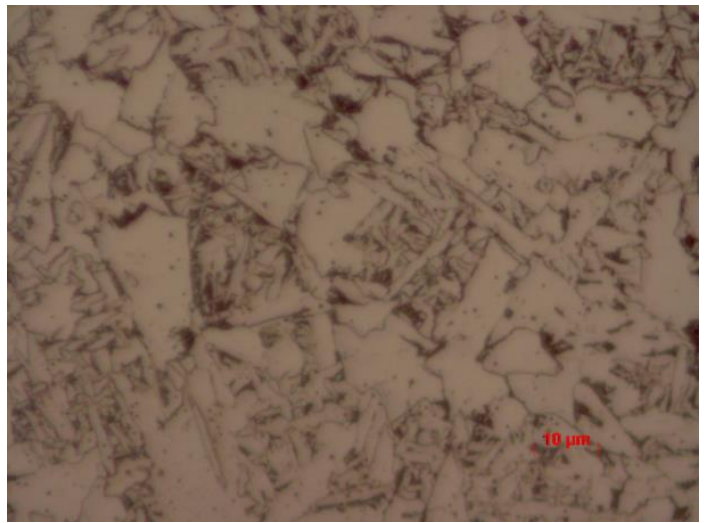

(b)

Figura 13: Microestrutura da zona fundida (ZF) submetida ao processo de solda com metal (a) Tipo A e (b) Tipo B

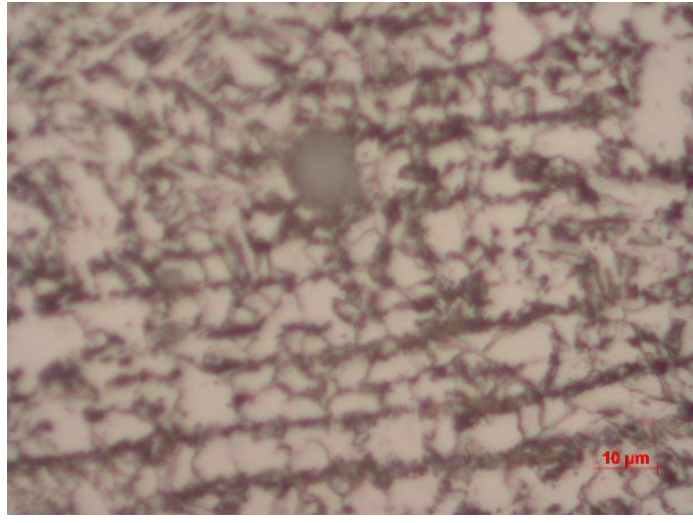

(a)

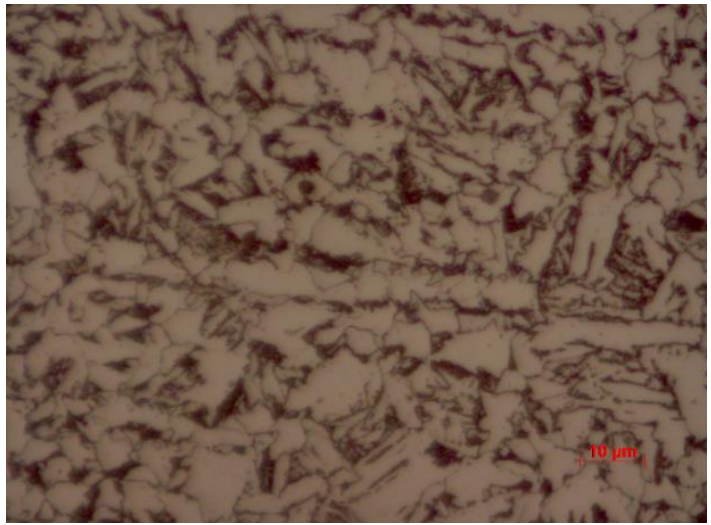

(b)

Figura 14: Microestrutura da zona termicamente afetada (ZTA) submetida ao processo de solda com metal (a) Tipo A e (b) Tipo B

Persp. Online: exatas \& eng., Campos dos Goytacazes, 25 (09) 20 - 48 - 2019 seer.perspectivasonline.com.br 


\subsection{Microdureza Vickers}

Os perfis de microdureza Vickers são apresentados na Figura 15.

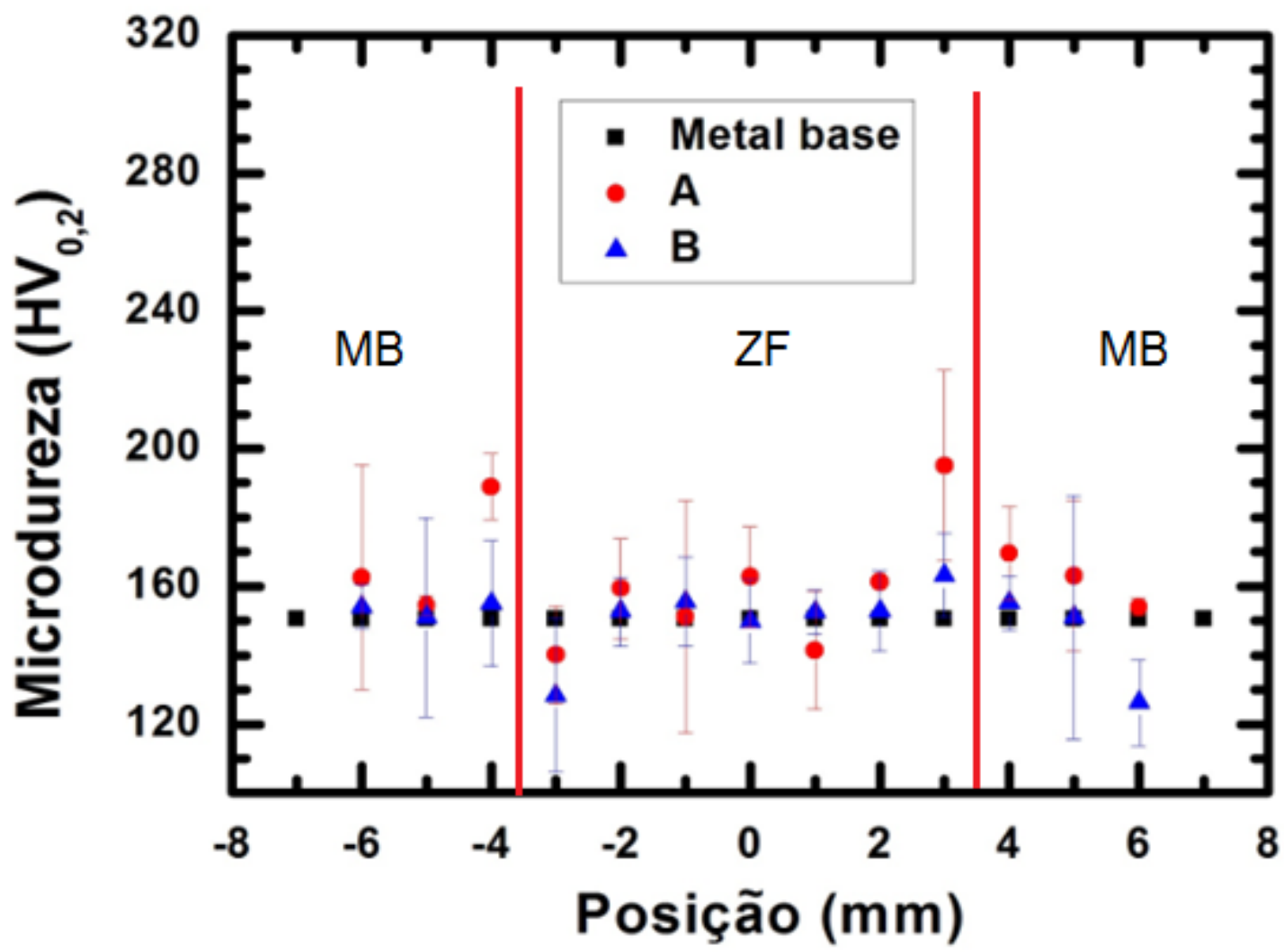

Figura 15: Perfil de microdureza do metal base (MB) submetido ao processo de soldagem com os consumíveis de solda tipo "A" e tipo "B".

Seguindo os requerimentos da norma SBM SPF92033 A1 (2009), os valores destes perfis se encontram abaixo do valor limite de $350 \mathrm{HV}$ especificados para aplicações deste material em sistemas contendo água do mar.

\subsection{Ensaio de Corrosão Eletroquímico}

3.4.1 Curva de estabilização de $E_{\text {corr }}$ vs. tempo e curva de polarização potenciodinâmica

A Figura 16 apresenta a curva de estabilização de potencial de corrosão versus tempo para as amostras obtidas à temperatura ambiente usando-se como solução corrosiva a solução de $\mathrm{H}_{2} \mathrm{SO}_{4}$ 0,5 moL/L. Observa-se a tendência de estabilizar o potencial entre $-0,47 \mathrm{a}-0,50$ VECS.

Pode-se observar nas Figuras 16 e 17 que o tipo de fluxante usado no processo de soldagem altera o comportamento da curva de polarização. Nota-se que as densidades de corrente para o metal de base soldado com metal "B" são menores do que as densidades de corrente do metal de base soldado com metal "A", e do que o próprio metal de base.

Persp. Online: exatas \& eng., Campos dos Goytacazes, 25 (09) 20 - 48 - 2019 seer.perspectivasonline.com.br 


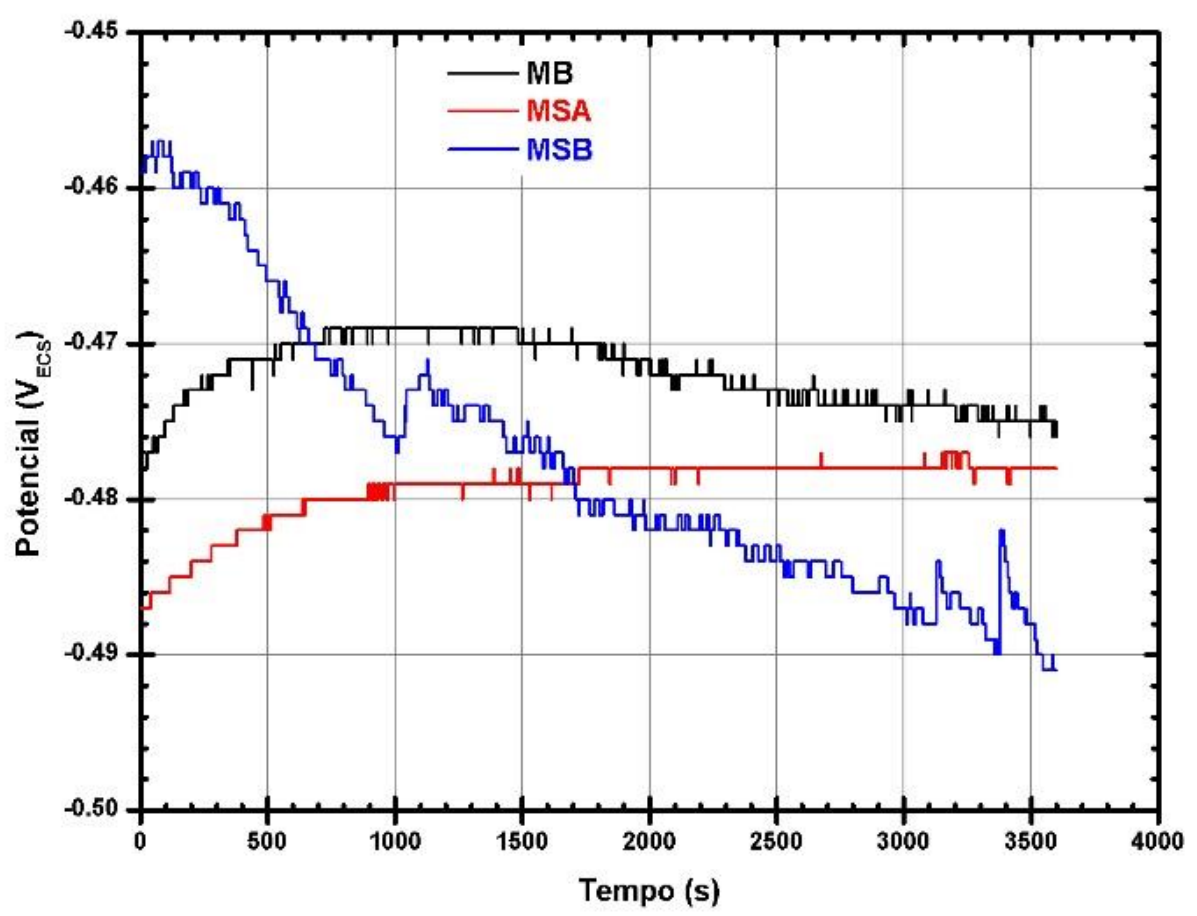

Figura 16: Curva de polarização potenciodinâmica experimental para as amostras avaliadas:

Potencial vs.Tempo

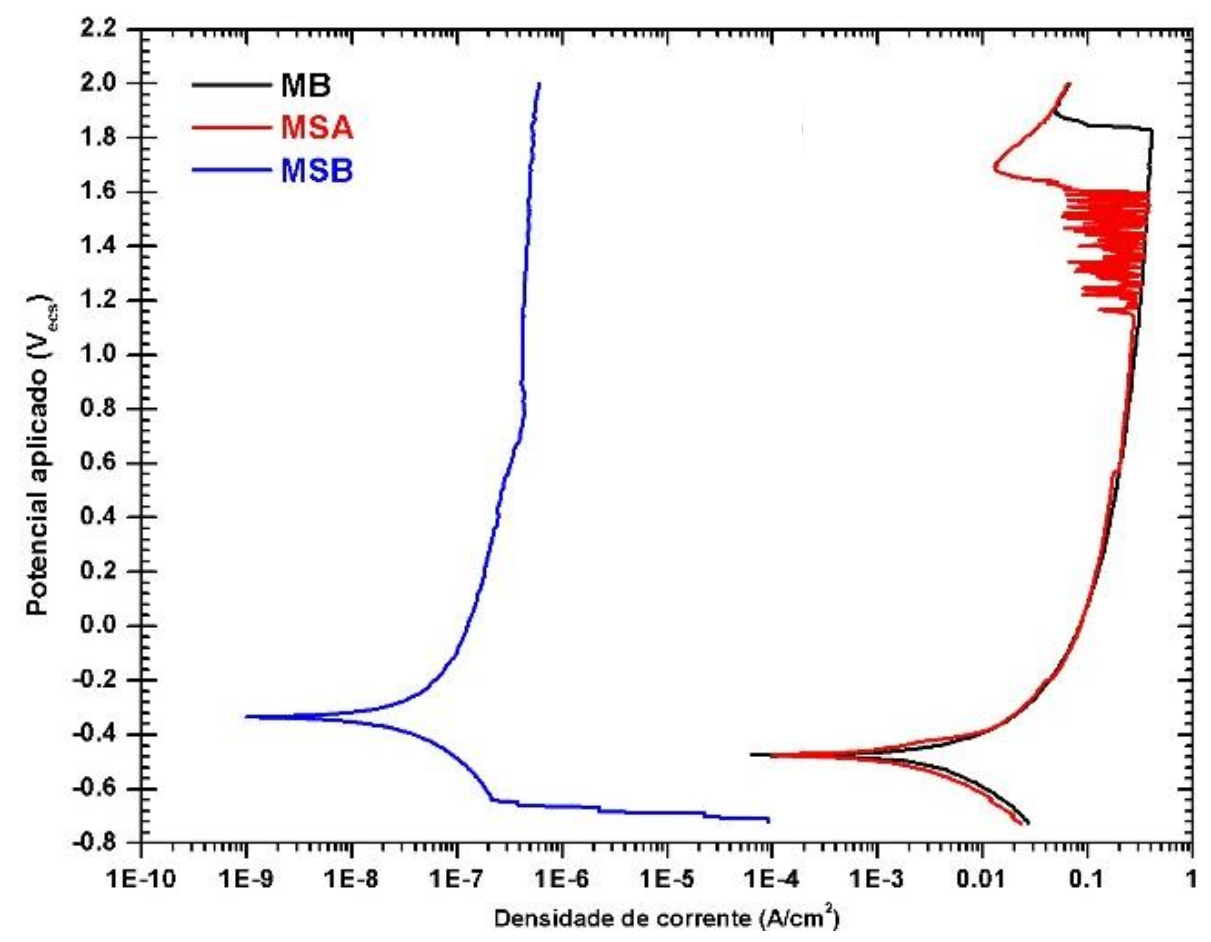

Figura 17: Curvas de polarização potenciodinâmica experimental para as amostras avaliadas: Potencial vs. Densidade de Corrente

A Tabela 10 apresenta os parâmetros eletroquímicos obtidos da curva de polarização potenciodinâmica, em solução $0,5 \mathrm{moL} / \mathrm{L}$ de $\mathrm{H}_{2} \mathrm{SO}_{4}$, na condição não aerada, à temperatura ambiente. Identifica-se nesta tabela: $\mathrm{E}_{\text {corr, }}$ potencial de corrosão, $\mathrm{I}_{\text {corr }}$, corrente de corrosão, $\beta_{\mathrm{a}}$, 
inclinação anódica da região de Tafel, $\beta_{c}$, inclinação catódica da região de Tafel, $R_{P}$ resistência de polarização pelo método potenciodinâmico e, $R_{\text {corr }}$ é a taxa de corrosão.

Tabela 10: Composição química dos materiais utilizados (\% em peso)

\begin{tabular}{c|c|c|c|c|c|c}
\hline Amostra & $\mathbf{E}_{\text {corr }}\left(\mathbf{m} V_{\text {ecs }}\right)$ & $\mathbf{I}_{\text {corr }}\left(\boldsymbol{\mu} \mathbf{A} / \mathbf{c m}^{2}\right)$ & $\boldsymbol{\beta}_{\mathbf{a}}(\mathbf{m V} / \mathbf{d e ́ c a d a})$ & $\boldsymbol{\beta}_{\mathbf{c}}(\mathbf{m V / d e ́ c a d a ) ~}$ & $\boldsymbol{R}_{\mathbf{P}}\left(\boldsymbol{\Omega . c m}^{2}\right)$ & $\mathbf{R}_{\text {corr }}(\mathbf{m m a})$ \\
\hline $\mathbf{M B}$ & $-477,7$ & 389,8 & 31 & 25 & 19,73 & 0,1151 \\
\hline MSA & $-477,1$ & 190,9 & 29 & 22 & 36,63 & 0,0564 \\
\hline MSB & $-500,0$ & 0,0169 & 500 & 500 & 0,5 & 0,127 \\
\hline
\end{tabular}

Observa-se na Tabela 10 que a amostra submetida ao processo de soldagem com metal A apresenta maior resistência à corrosão. Observa-se que os potenciais de corrosão não são influenciados pelo metal de adição na soldagem.

\subsubsection{Diagrama de espectroscopia de impedância eletroquímica}

A Figura 18 apresenta os diagramas de Nyquist simulados para as amostras avaliadas. Como mostra a Figura 18, o mecanismo de controle do processo de corrosão é cinético seguido por adsorção superficial para o metal se soldado base e para a amostra com solda com metal de adição "A". No entanto, o mecanismo de controle para a amostra de metal de base soldado com metal "B" é puramente cinético de transferência de carga elétrica na interface metal eletrólito. A Tabela 11 apresenta os dados eletroquímicos extraídos destes diagramas.

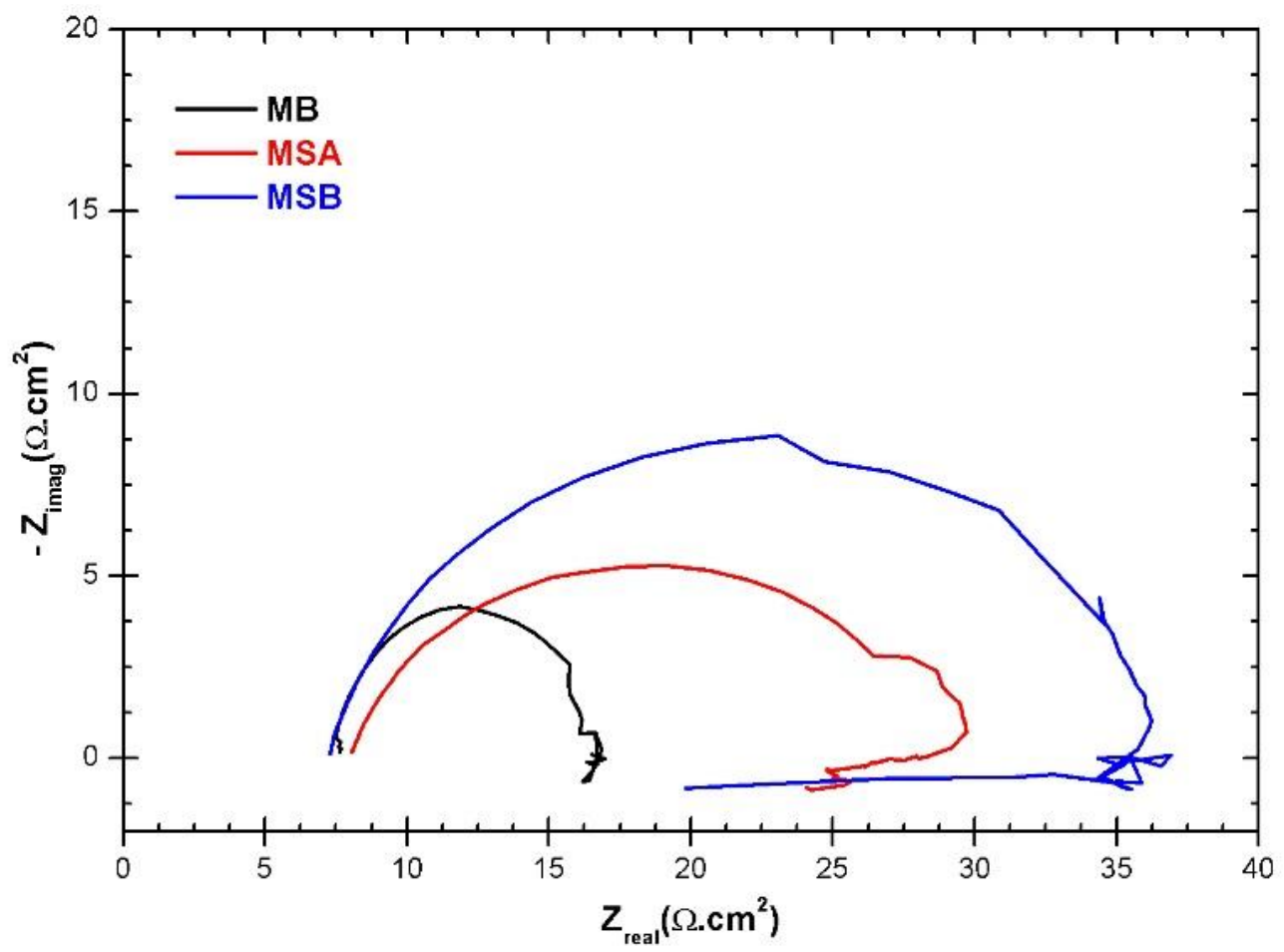

Figura 18: Diagrama de espectroscopia de impedância eletroquímica - Diagrama de Nyquist 
Tabelas 11: Parâmetros eletroquímicos das amostras avaliadas, extraídos dos diagramas de espectroscopia de impedância eletroquímica - Diagrama de Nyquist - em solução $\mathrm{H}_{2} \mathrm{SO}_{4} 0,5$ moL/L, na condição não aerada, à temperatura ambiente

\begin{tabular}{|c|c|c|c|}
\hline Parâmetro & MB & MSA & MSB \\
\hline $\mathbf{R}_{\text {eletrólito }}\left(\boldsymbol{\Omega . \mathrm { cm } ^ { 2 }}\right)$ & 4,63 & 6,28 & 4,52 \\
\hline $\mathbf{Q}\left(\mathbf{S} . \mathrm{s}^{\mathrm{n}}\right) \cdot \mathrm{cm}^{-2}$ & 0,000498 & 0,000442 & 0,000430 \\
\hline $\mathbf{N}$ & 0,911 & 0,852 & 0,930 \\
\hline $\mathbf{R}_{1}\left(\Omega . \mathrm{cm}^{2}\right)$ & $6,84 \times 10^{6}$ & 16,88 & 17,71 \\
\hline $\mathbf{L}_{1}\left(\mathbf{H}_{.} \mathrm{cm}^{2}\right)$ & 23,39 & 880,1 & - \\
\hline $\mathbf{R}_{2}\left(\Omega . \mathrm{cm}^{2}\right)$ & 207,9 & 110,4 & - \\
\hline $\mathbf{L}_{2}\left(\mathbf{H} . \mathrm{cm}^{2}\right)$ & 0,00101 & 25,23 & - \\
\hline $\mathbf{R}_{\mathbf{3}}\left(\mathbf{\Omega . c m ^ { 2 }}\right)$ & 5,755 & 102,1 & - \\
\hline \multicolumn{4}{|c|}{ Circuito elétrico equivalente } \\
\hline
\end{tabular}

O tipo de fluxante usado no processo de soldagem altera o comportamento eletroquímico do metal base, como se observa nas diferentes curvas de polarização potenciodinâmicas obtidas. Em termos de resistência à corrosão eletroquímica, dada por $\mathrm{R}_{\text {corr, }}$ pode-se dizer que MSA > $\mathrm{MB}>\mathrm{MSB}$.

\subsection{Simulações no software Abaqus do ensaio de tração}

Os dados simulados no Abaqus e os dados dos ensaios de tração foram compilados e gerou-se as curvas de tensão versus deformação para cada tipo de corpo de prova. Os resultados gerados nas simulações são baseados em força versus tempo de ensaio com base nos incrementos de interações, assim é possível fazer uma correlação entre as curvas.

As Figuras 19, 20 e 21 mostram as curvas de tensão versus deformação simulada no Abaqus, assim como as curvas de tensão versus deformação realizada dos corpos ensaiados do aço ASTM A572. 


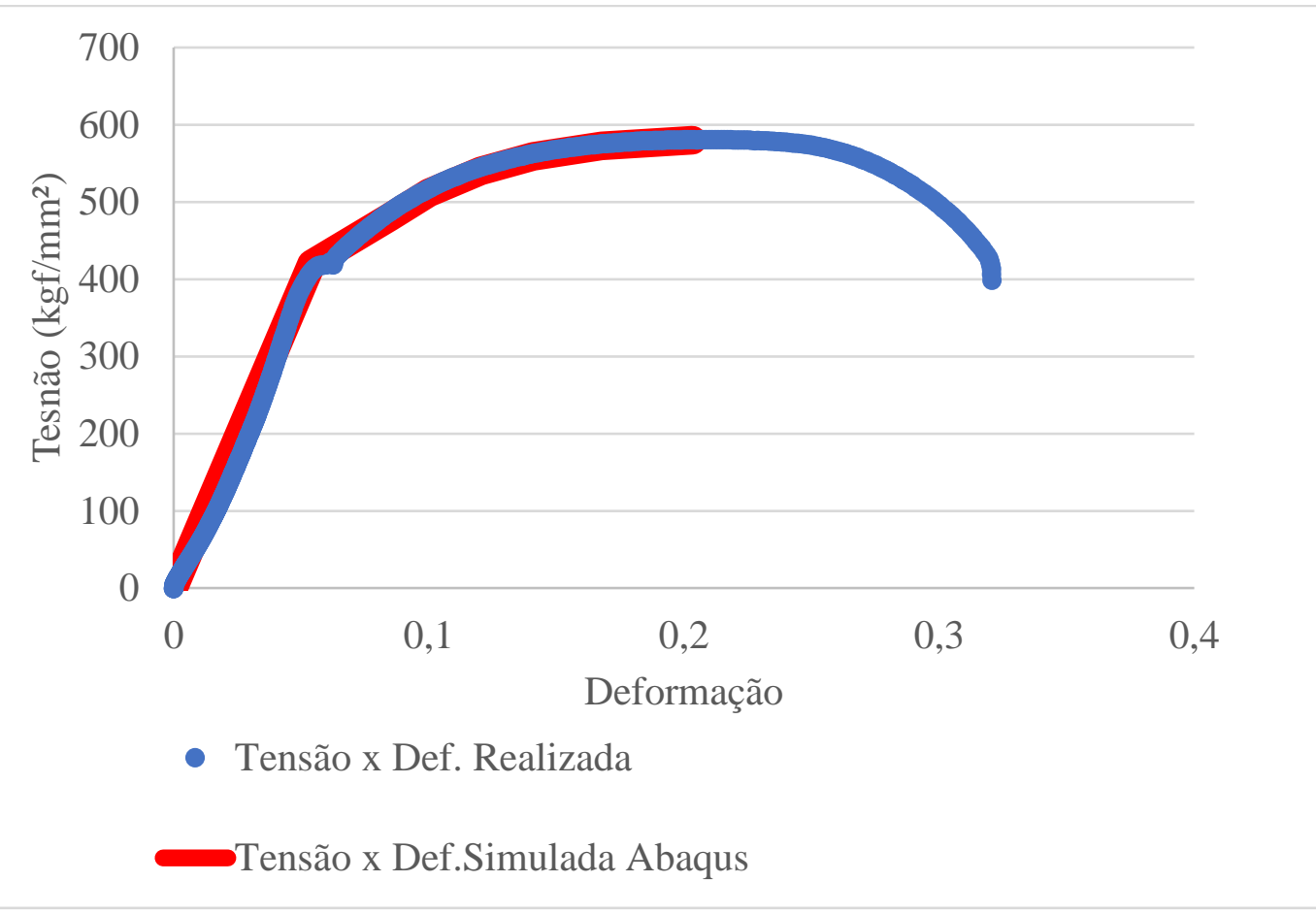

Figura 19: Aço ASTM A572 corpo de prova Metal base - Curvas tensão x deformação

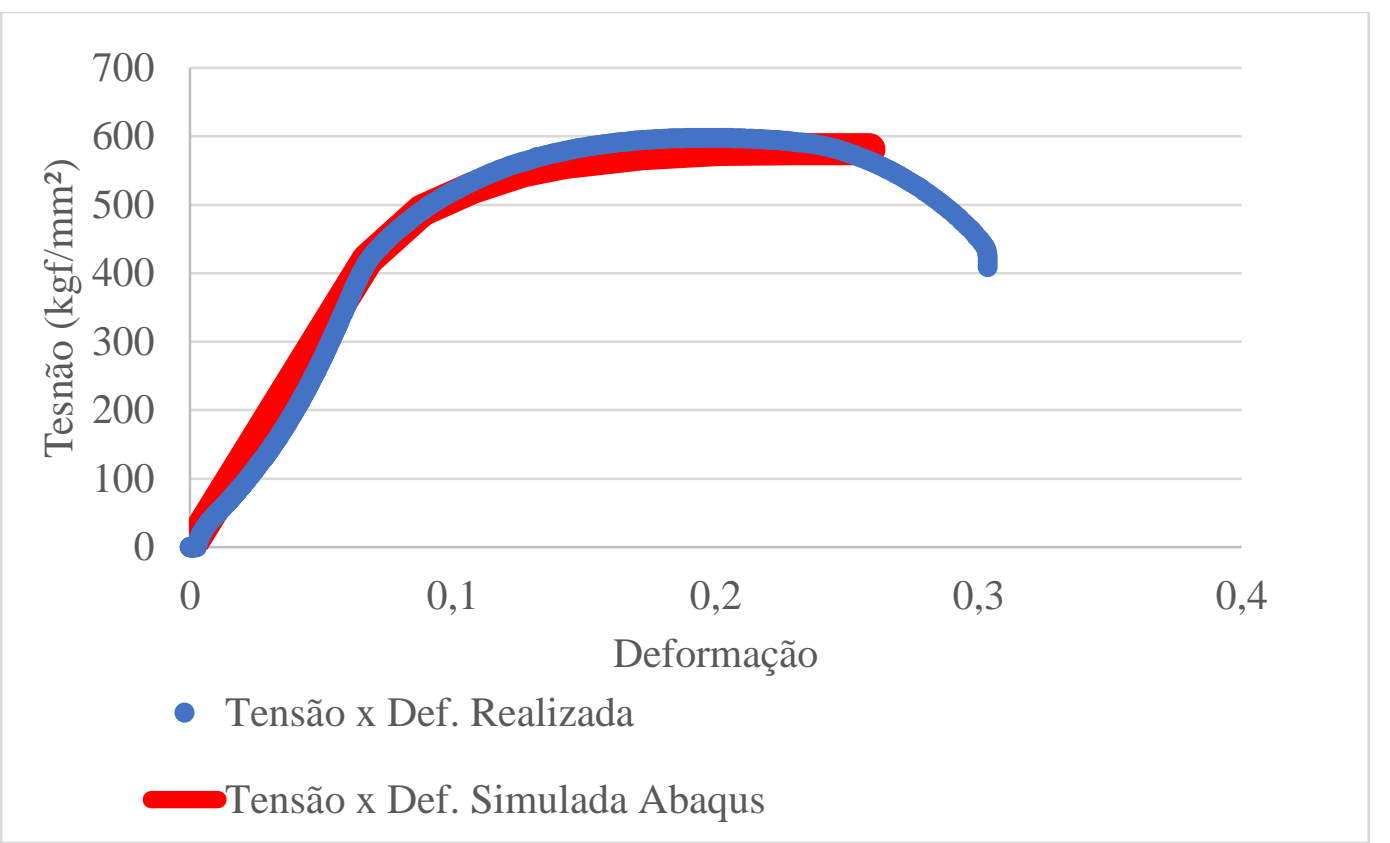

Figura 20: Aço ASTM A572 corpo de prova do tipo "A" - Curvas tensão x deformação 


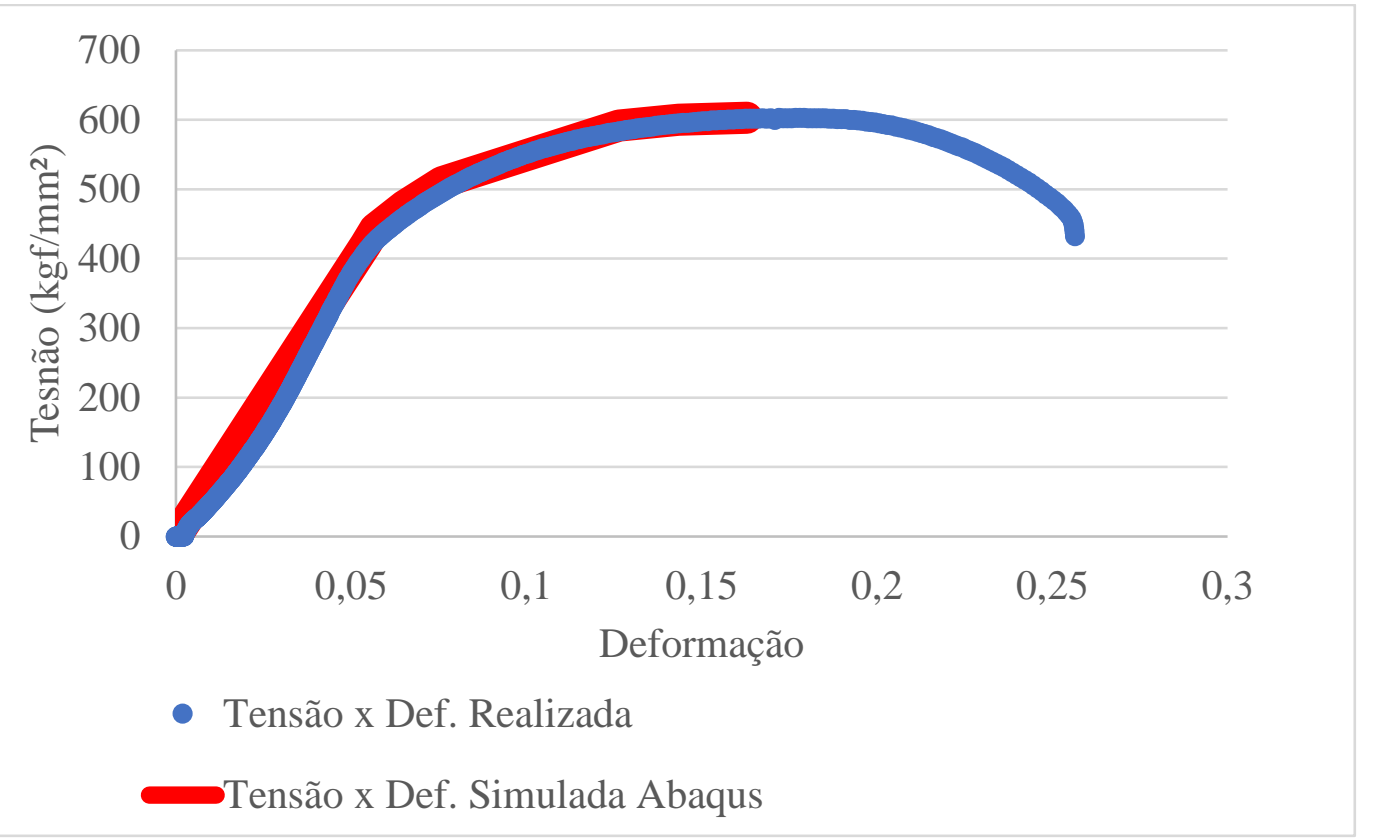

Figura 22: Aço ASTM A572 corpo de prova do tipo "B" - Curvas tensão x deformação

As Figuras 22, 23 e 24 mostram as curvas de tensão versus deformação verdadeira simulada no Abaqus, assim como as curvas de tensão versus deformação verdadeira dos corpos ensaiados do aço ASTM A572.

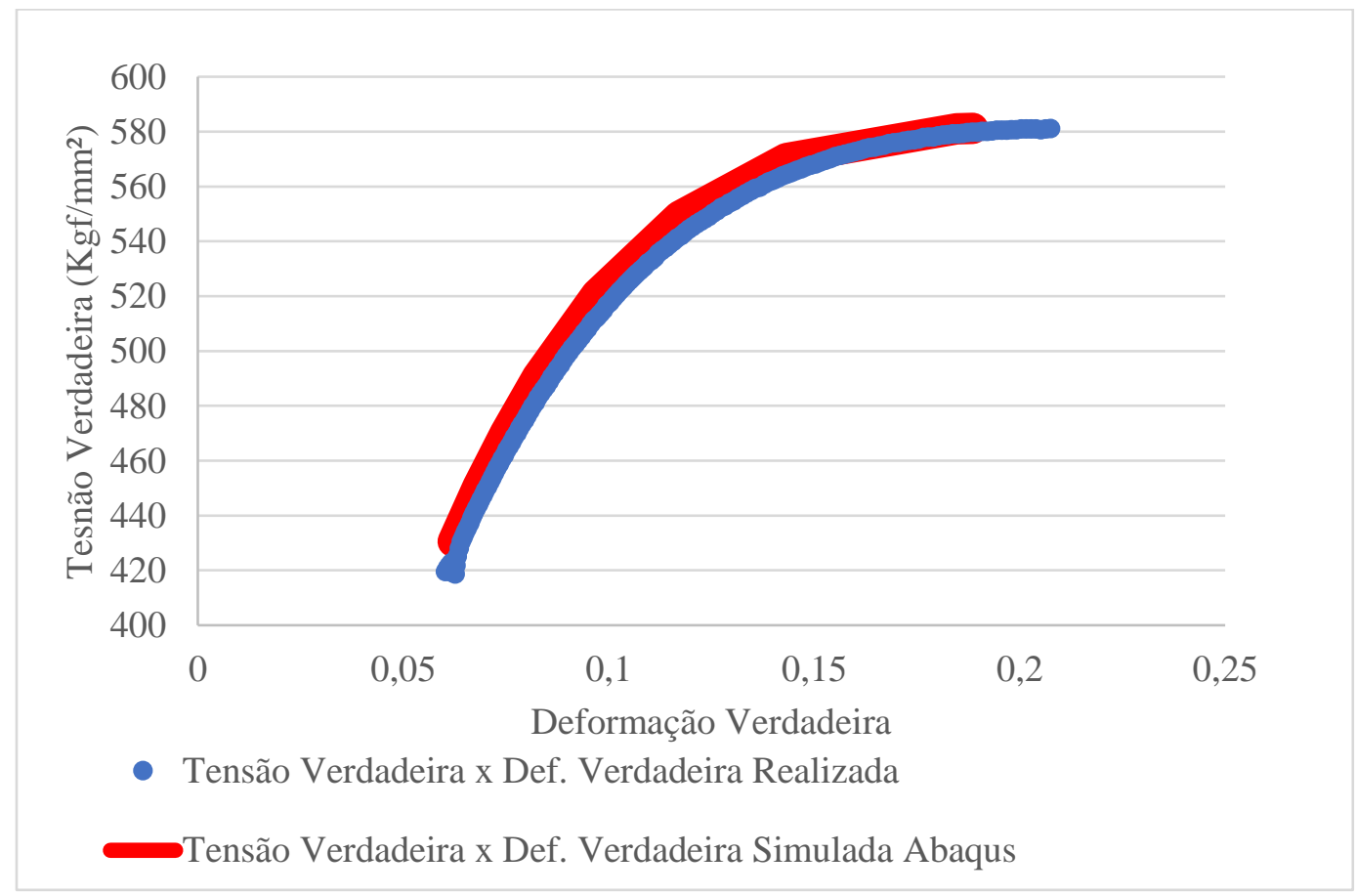

Figura 22: Aço ASTM A572 corpo de prova Metal base - Curva tensão verdadeira X deformação verdadeira

Persp. Online: exatas \& eng., Campos dos Goytacazes, 25 (09) 20 - 48 - 2019 seer.perspectivasonline.com.br 


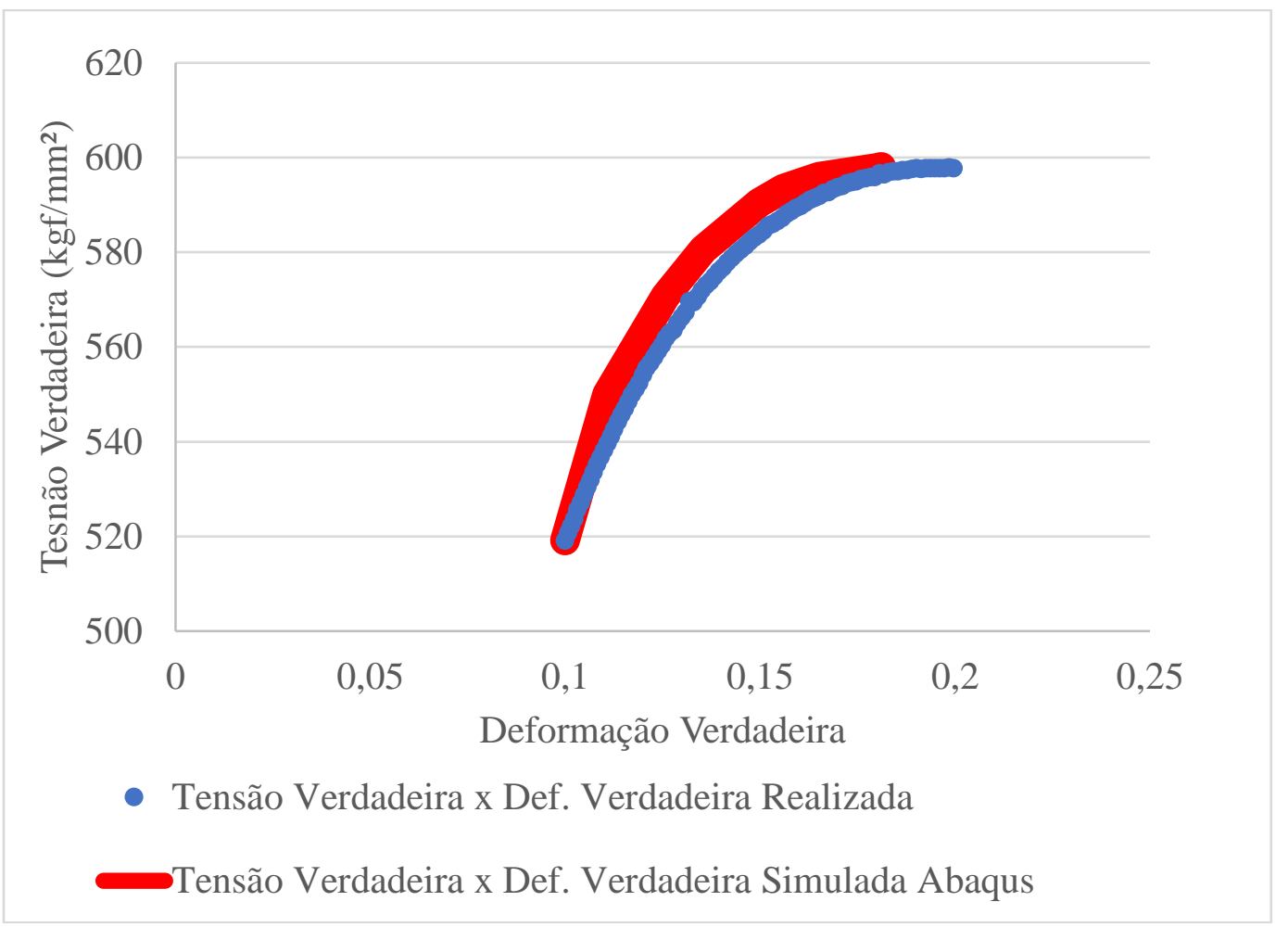

Figura 23: Aço ASTM A572 corpo de prova do tipo "A" - Curvas tensão verdadeira X deformação verdadeira

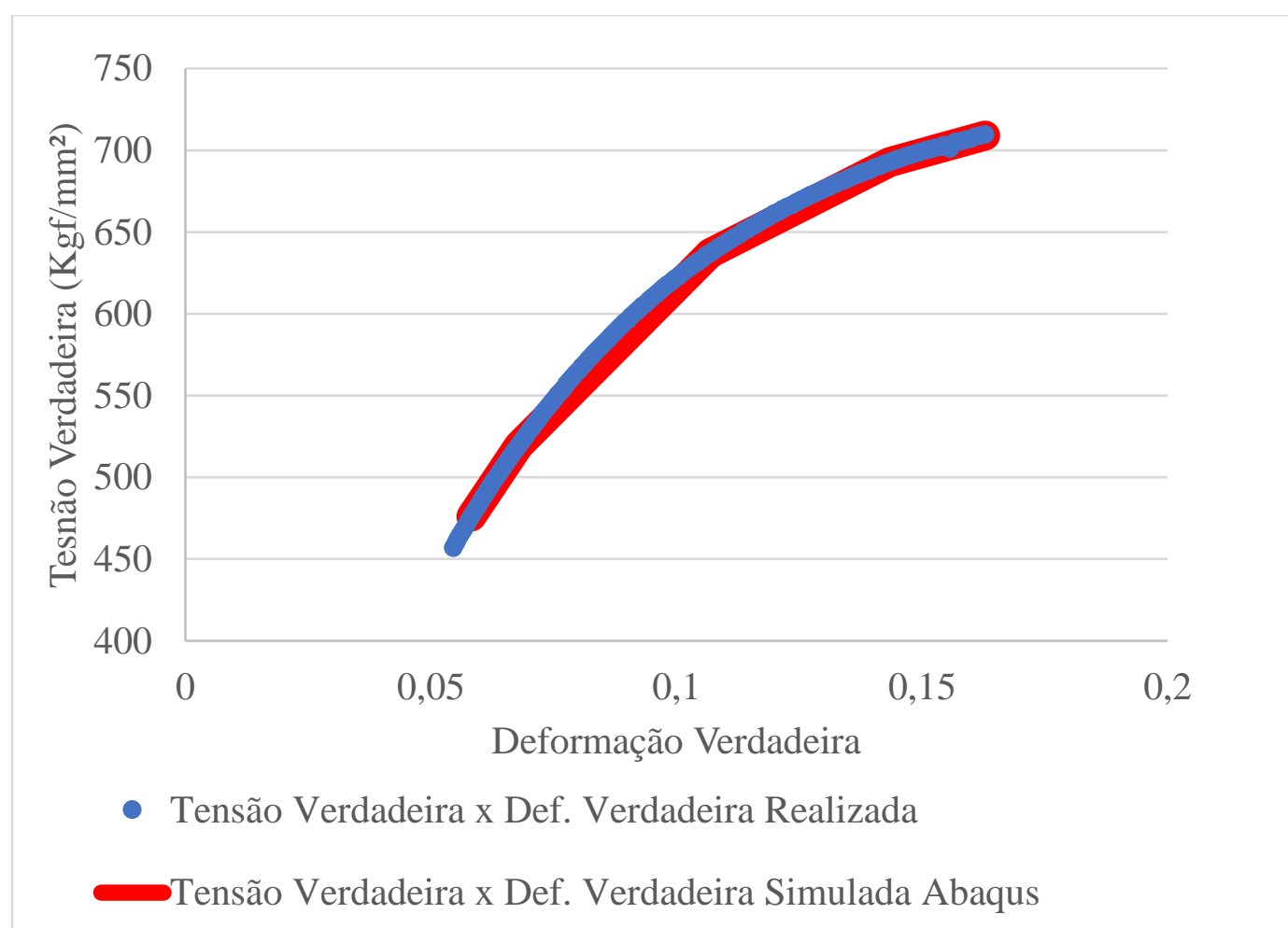

Figura 24: Aço ASTM A572 corpo de prova do tipo “B” - Curvas tensão verdadeira x deformação verdadeira

Os resultados da simulação no Abaqus nos corpos de prova para análise dos testes de tração no aço ASTM A572 após a deformação são apresentados nas Figuras 25, 26 e 27.

Persp. Online: exatas \& eng., Campos dos Goytacazes, 25 (09) 20 - 48 - 2019 seer.perspectivasonline.com.br 


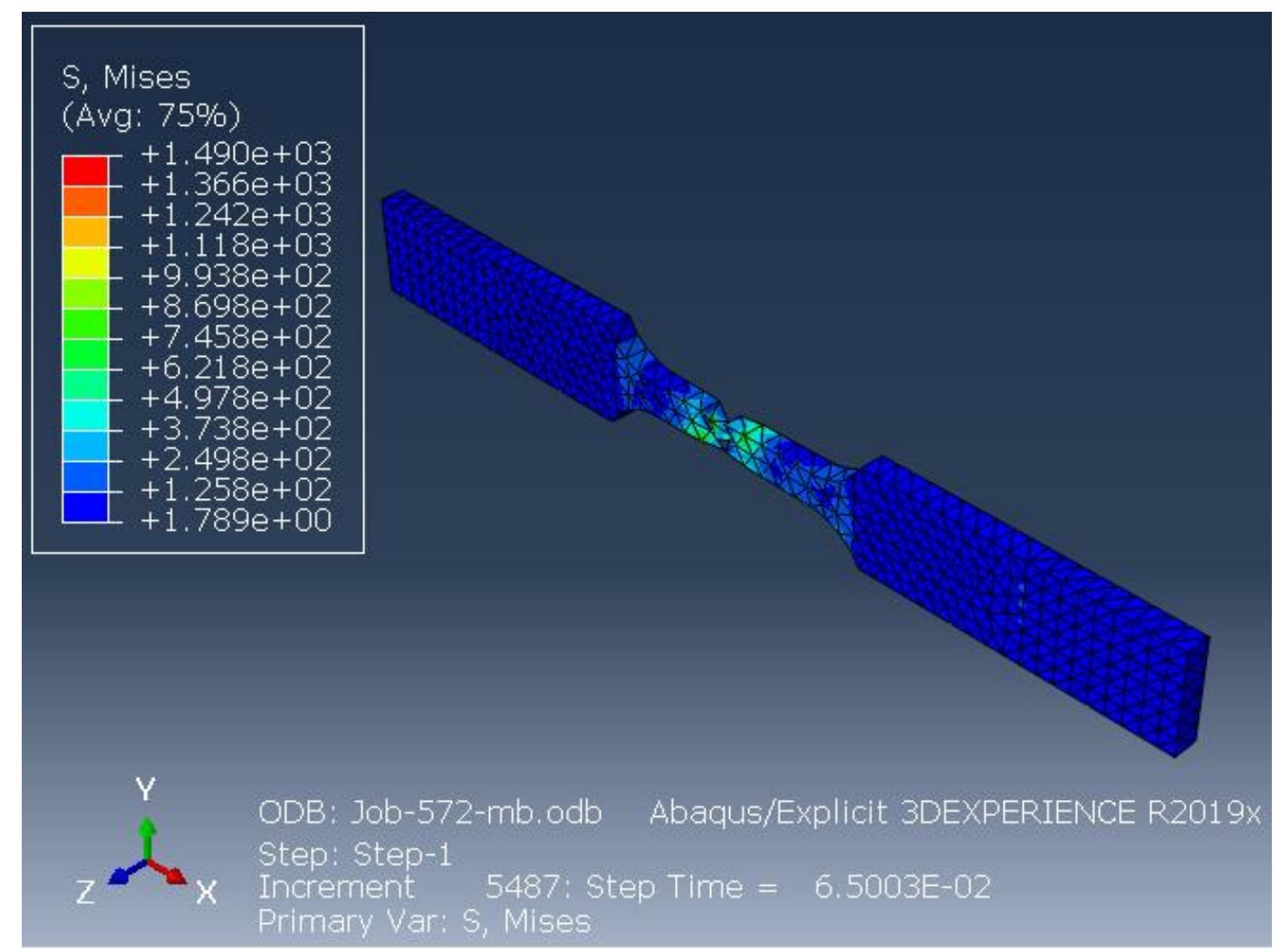

Figura 25: Aço ASTM A572 corpo de prova Metal base - Corpo de prova virtual após a deformação simulação do Abaqus

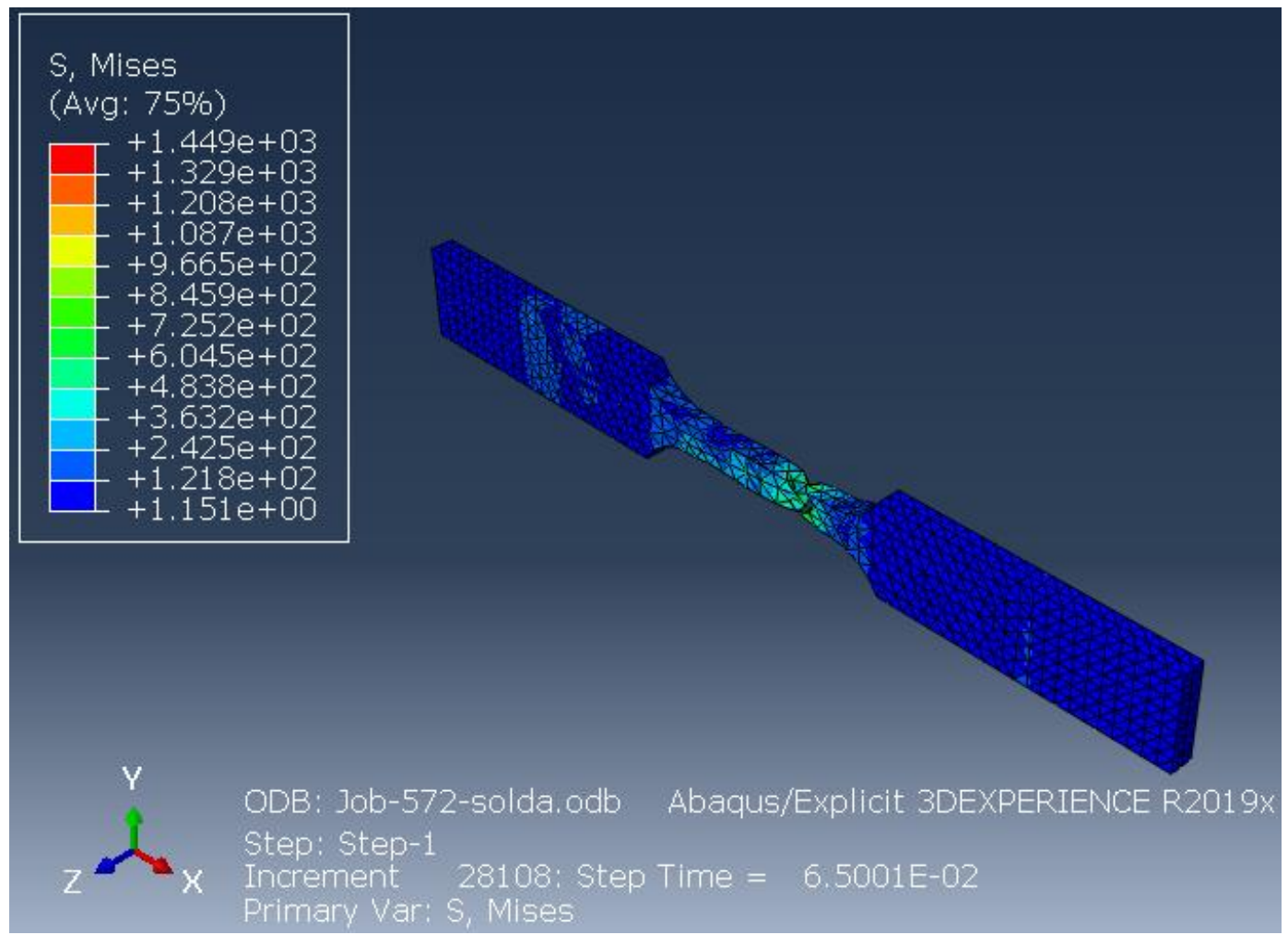

Figura 26: Aço ASTM A572 corpo de prova do tipo "A" - Corpo de prova virtual após a deformação simulação do Abaqus

Persp. Online: exatas \& eng., Campos dos Goytacazes, 25 (09) 20 - 48 - 2019 seer.perspectivasonline.com.br 


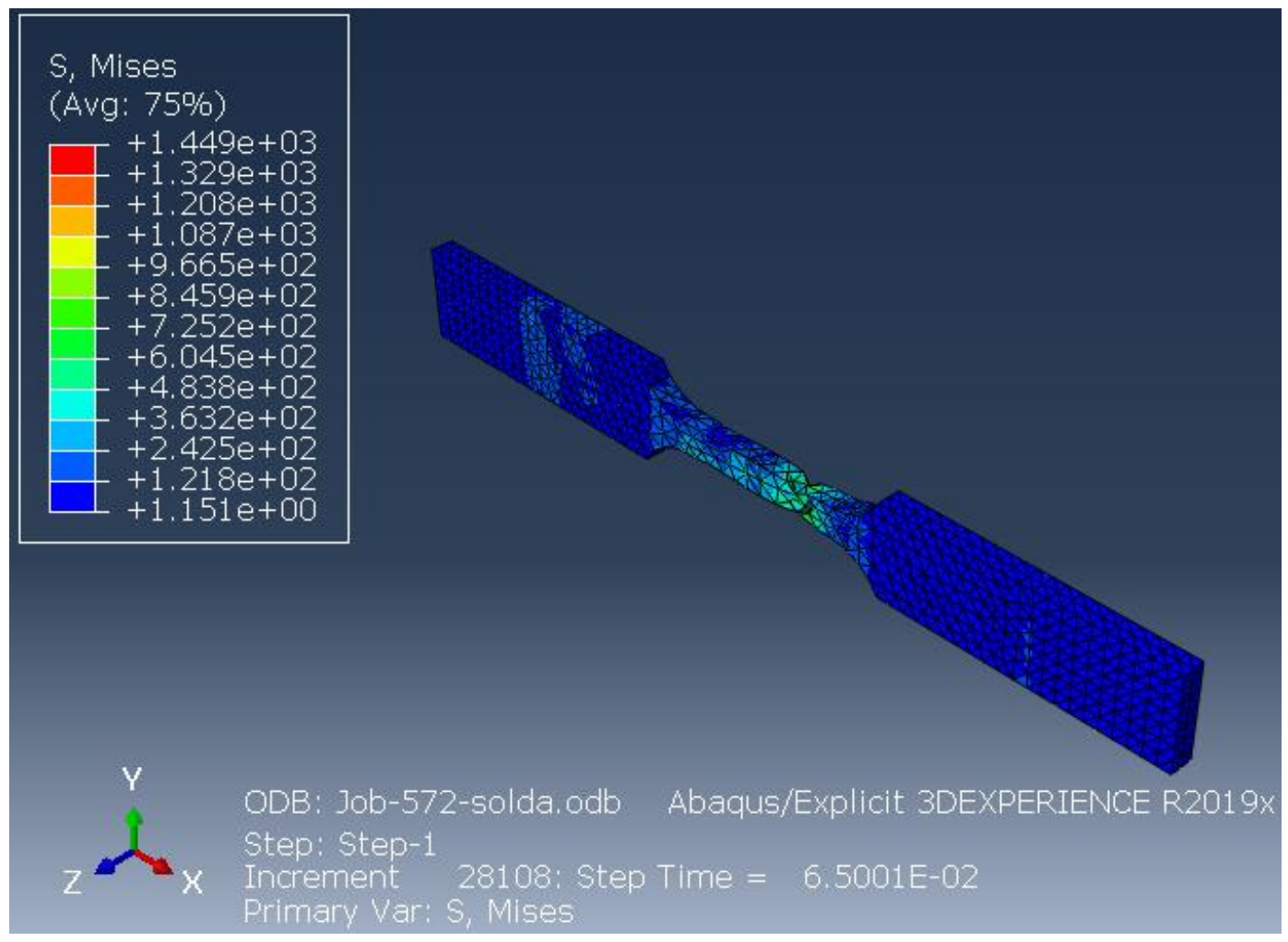

Figura 27: Aço ASTM A572 corpo de prova do tipo "B" - Corpo de prova virtual após a deformação simulação do Abaqus

Os resultados dos corpos de prova real ensaiado e simulado do aço ASTM A572 após a deformação são apresentados em escala nas Figuras 28 e 29.
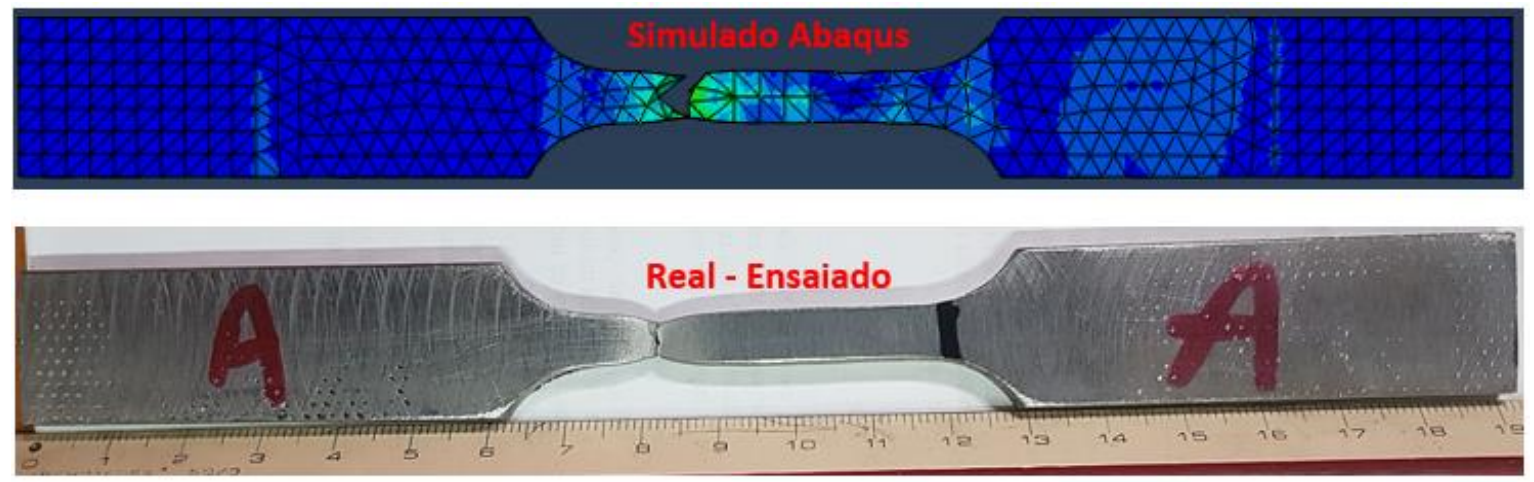

Figura 28: Aço ASTM A572 corpo de prova do tipo "A" - Corpos de prova real ensaiado e simulado após a deformação

Persp. Online: exatas \& eng., Campos dos Goytacazes, 25 (09) 20 - 48 - 2019 seer.perspectivasonline.com.br 

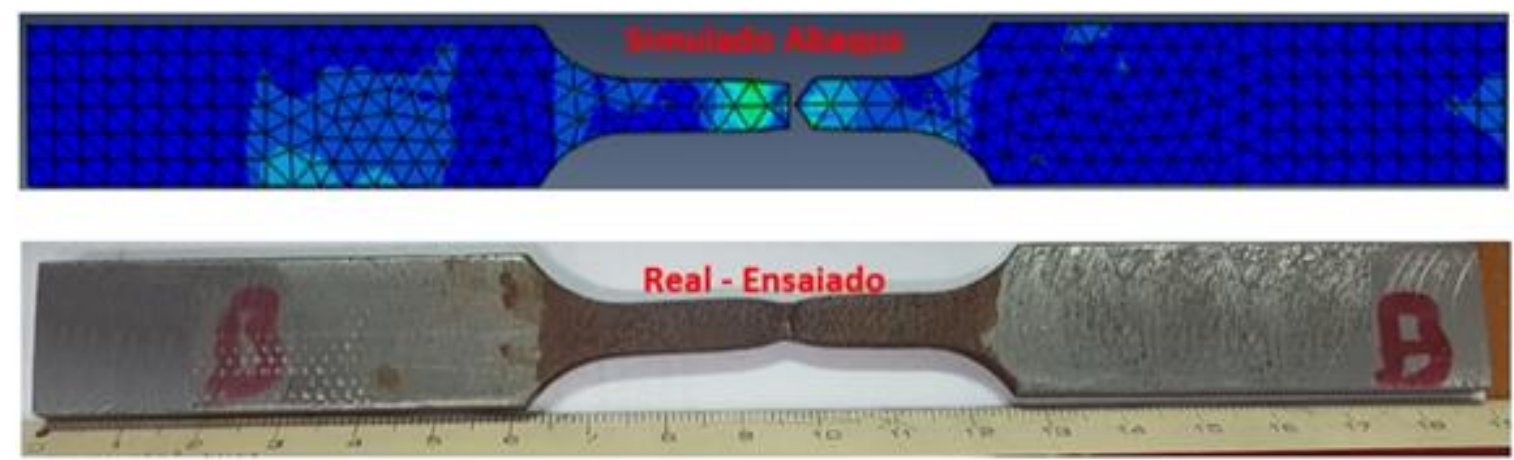

Figura 29: Aço ASTM A572 corpo de prova do tipo "B" - Corpos de prova real ensaiado e simulado após a deformação

A estricção se deu em locais similares dos corpos de prova, conforme mostrado nas Figuras 25, 26 e 27, o que não demonstrou uma presença de concentrador de tensões (SIMULATION TOOLS, 2002). As Figuras 28 e 29 comparam os corpos de prova reais ensaiados versus os simulados e mostra as estricções reais de forma similar às que foram encontradas nas simulações executadas no Abaqus.

A simulação numérica do ensaio de tração por elementos finitos utilizando o Abaqus do Aço ASTM A572 metal base e juntas soldadas, mostrou-se eficiente e confiável quando comparados com os ensaios de tração realizados na máquina de ensaios universal. As curvas seguiram de forma paralela no regime elástico, tendo valores um pouco menores favorecendo o limite de segurança. Assim, os efeitos de falhas internas passam não ser preponderante no uso desta ferramenta (DIETER, 1984).

Em ambos os casos, os modelos empregados foram capazes de reproduzir o fenômeno de aumento da rigidez e do limite de resistência mecânica do material, conforme pode ser observado nas Figuras 18, 19 e 20. Foram obtidos valores do limite de resistência ligeiramente superiores aos obtidos experimentalmente. A ruptura dos corpos de provas na simulação ocorreu em níveis de deformação inferiores aos observados nos ensaios mecânicos, com a maior discrepância de 3,0\% (HANASHIRO, 2005).

\section{CONCLUSÕES}

Neste trabalho, juntas soldadas por GMAW - MAG e FCAW do aço ASTM A572 foram analisadas. Foi verificado que a extensão da ZTA formada em ambos casos não excede $0,5 \mathrm{~mm}$. Além disso, não se observou a presença de descontinuidades de soldagens, tais como poros e/ou trincas. A microestrutura do metal base ASTM A572 é constituída de grãos de ferrita e de perlita e após a soldagem não foi verificada a formação de microconstituintes duros e fragilizantes. $\mathrm{O}$ mesmo foi comprovado através dos ensaios de microdureza Vickers.

Ao analisar a resistência à corrosão eletroquímica numa solução de ácido sulfúrico $(0,5$ moL/L), observou-se através da análise das curvas de polarização potenciodinâmicas obtidas que o tipo de fluxante usado no processo de soldagem altera o comportamento eletroquímico do metal base, verificando-se que a resistência à corrosão eletroquímica do MSA é maior que a do MB, que por sua vez é maior que a do MSB.

Além disso, o modelo de simulação empregado mostrou-se eficiente, sendo capaz de reproduzir o fenômeno do aumento da rigidez e do limite de resistência mecânica do material.

Persp. Online: exatas \& eng., Campos dos Goytacazes, 25 (09) 20 - 48 - 2019 seer.perspectivasonline.com.br 


\section{REFERÊNCIAS}

Abaqus, Abaqus/CAE User's Manual. Disponível em: http://abaqusdoc.ucalgary.ca/books/usb/default.htm?startat=pt04ch11s04aus66.html, Acesso em Junho, 2019.

AMERICAN SOCIETY FOR TESTING AND MATERIALS. ASTM G5. Standard Reference Test Method for Making Potentiodynamic Anodic Polarization Measurements. Philadelphia. 2013.

AMERICAN SOCIETY FOR TESTING AND MATERIALS. ASTM G106. Standard Practice for Verification of Algorithm and Equipment for Electrochemical Impedance Measurements. Philadelphia. 2010.

CALLISTER, W. D., Ciência e Engenharia de Materiais: Uma Introdução. John Wiley \& Sons, Inc., 2002.

COLPAERT, H. (1994). Metalografia dos produtos siderúrgicos comuns. In: Metalografia dos produtos siderúrgicos comuns. Edgard Blucher.

DAVIS, J.R. Introduction to Tensile Testing. ASM INTERNATIONAL. Disponível em: Http://www.asminternational.org/Template.cfm?Section=NewProducts\&template=Ecommerc e/FileDisplay.cfm\&file=5106_ch01.pdf $>$. Acesso em Junho, 2019.

DIETER, G. E. Workability testing techniques. American Society for Metals, 1984,, p. 324, 1984.

FERRER, M. H.. Tenacidade à fratura do aço AISI/SAE- 4140 quando tratado através de têmpera e partição. 2013. 52 p. Monografia (Bacharelado). Joinville: Ufsc, 2013.

GABRIELLI, C. Identification of electrochemical processes by frequency response analysis. Solartron Analytical Technical Report 004/83, pp. 1-119. 1998.

GORNI, A. A. Aços avançados de alta resistência: microestrutura e propriedades mecânicas. Corte e Conformação de Metais, v. 4, n. 44, p. 26-57, 2008.

HANASHIRO. J. Comparison and Evaluation of results of Traction Tests of Elastomeric Compounds obtained in Practice and obtained by Mathematical Modeling. 2005. 127p. Polytechnic School of the University of São Paulo. São Paulo, 2005.

JONES, Denny A. Principles and Prevention of Corrosion. 2.ed. Upper Saddle River. Prentice-Hall, 1996.

MATTOS, O. R. Acompanhamento do processo de deterioração de revestimentos com o auxílio da técnica de impedância eletroquímica. Rev. Ibero. Corros. y Prot.,v. XVIII, n. 1, p. 43-48, 1987.

ORAZEM, M. E.; TRIBOLLET, B. Electrochemical Impedance Spectroscopy. New Jersey: John Wiley \& Sons, Inc., Hoboken, USA. 523p. 2008.

Persp. Online: exatas \& eng., Campos dos Goytacazes, 25 (09) 20 - 48 - 2019 seer.perspectivasonline.com.br 
PADILHA A. F., AMBROSIO F. F. Técnicas de analise microestrutural, São Paulo: Ed. Hemus, 1985, 190p.

PEDEFERRI, P. Corrosion Science and Engineering. Edited by Luciano Lazzari and Maria Pia Pedeferri. Switzerland: Springer Nature Switzerland AG. 2018. 720p.

RIVA, P. D. Modelagem Tridimensional do Ensaio de Tenacidade à Fratura com o Software Abaqus, Simpósio de Métodos Numéricos em Engenharia, Universidade Federal de Paraná Curitiba, Brasil. 2017.

SBM SPF 92033 A1: FPSO, Fabrication, Welding and Erection Specification, 2009.

SIMULATION TOOLS IN MECHANICS: FINITE ELEMENTS. Material compiled for the discipline of Finite Elements for Graduation and Post-graduation in Mechanical Engineering. UFRGS. 2002.

WOLYNEC, S. Técnicas Eletroquímicas em Corrosão. São Paulo: EDUSP - Editora da Universidade de São Paulo. 2003. 166 p. 